NBER WORKING PAPER SERIES

\title{
DEPRIVATION AND DISEASE IN EARLY \\ TWENTIETH-CENTURY AMERICA
}

\author{
Karen Clay \\ Werner Troesken \\ Working Paper 12111 \\ http://www.nber.org/papers/w12111
}

\author{
NATIONAL BUREAU OF ECONOMIC RESEARCH \\ 1050 Massachusetts Avenue \\ Cambridge, MA 02138 \\ March 2006
}

Troesken gratefully acknowledges grant support from the NIA/NIH, P01 AG10120. The views expressed herein are those of the author(s) and do not necessarily reflect the views of the National Bureau of Economic Research.

(C)2006 by Karen Clay and Werner Troesken. All rights reserved. Short sections of text, not to exceed two paragraphs, may be quoted without explicit permission provided that full credit, including $\odot$ notice, is given to the source. 
Deprivation and Disease in Early Twentieth-Century America

Karen Clay and Werner Troesken

NBER Working Paper No. 12111

March 2006

JEL No. I3, N3

\begin{abstract}
$\underline{\text { ABSTRACT }}$
This paper explores how early life exposure to poverty and want adversely affects later life health outcomes. In particular, it examines how exposure to crowded housing conditions and impure drinking water undermines long-term health prospects and increases the risk of age-related pathologies such as cancer, heart disease, kidney disease, and stroke. Exploiting city-level data from early-twentieth century America, evidence is presented that cities with unusually high rates of typhoid fever in 1900 had elevated rates of heart and kidney disease fifteen years later; also cities with unusually high rates of tuberculosis in 1900 had elevated rates of cancer and stroke fifteen years later. The estimated coefficients suggest that eradicating typhoid fever (through water purification) and tuberculosis (through improved housing and nutrition) would have reduced later death rates from heart disease, cancer, stroke, and kidney disease by 23 to 35 percent.
\end{abstract}

\author{
Karen Clay \\ Carnegie Mellon University \\ 5000 Forbes Ave. \\ Pittsburgh, PA 15217 \\ kclay@andrew.cmu.edu \\ Werner Troesken \\ Department of History \\ University of Pittsburgh \\ Pittsburgh, PA 15260 \\ and NBER \\ troesken@pitt.edu
}

Heinz School of Public Policy and Management 


\section{Introduction}

That material deprivation is associated with disease is not especially controversial. Demographers and economists have long recognized that the poor tend to live short, wretched lives (Alison 1842; Griffin 1841; Sykes 1850; Stevenson 1921; and Haines 1995). Indeed, one might even argue that there is a class of diseases that should be called diseases of deprivation. The obvious candidates to place in such a category would be pathologies that are highly correlated with poverty and want, diseases like typhoid fever and tuberculosis. Typhoid, a disease spread mainly through water contaminated with human fecal matter, is largely unheard of in the developed world. It persists only in those countries too poor to finance the infrastructure necessary to purify and distribute water (Crump et al. 2004). Similarly, tuberculosis is most common in the poorest nations, and although it continues to afflict some populations in wealthier countries, it is concentrated among disadvantaged groups (Dye et al. 1999).

Less obvious, however, is the classification of cancer, heart disease, kidney disease, and other age-related pathologies. One might argue that heart disease and certain forms of cancer are diseases of excessive wealth, the result of years of idle chatter, fine wine, and rich food. Historically, physicians and medical experts often attributed gout, heart problems, and a variety of otherwise mysterious ailments among the wealthy to their sedentary and decadent lifestyle and to a diet laden with fat and alcoholic spirits (Appleby 1979; Horrocks 1995; Pollock 1990). Along the same lines, it is possible that because the poor died mainly from infectious diseases, they did not live long enough to die from diseases of old age like cancer 
and heart disease. On the other hand, there is much evidence to suggest that exposure to infectious diseases early in life adversely affects later life health outcomes (Almond 2005; Barker 1992 and 1994; Bengtsson and Lindstrom 2000; Leon and Smith 2000). To the extent that the poor were exposed to more infections early in life, they might have been at greater risk for developing heart problems, cancer, and other pathologies later in life (Dorling et al. 2005; Macleod et al. 2005).

Revisiting the classification of diseases of deprivation, this paper explores the possibility that material want at an early life stage increases the risk of various age-related diseases at a later life stage. The paper is predicated on two indicators of early-life poverty, overcrowded housing and impure drinking water. There are, in turn, two specific physiological pathways through which substandard housing and tainted water supplies might adversely affect later-life health outcomes. Crowded and poorly-ventilated housing is correlated with tuberculosis (McSherry and Connor 1993; Elender et al. 1998; Reinhard et al. 1997), and prior exposure to tuberculosis is a risk factor for cancer and stroke (Wu et al. 1995; Pananini-Hill et al. 2003). Impure drinking water is the primary cause of typhoid fever (Budd 1877), and common sequella of typhoid include heart and kidney disease (Dublin 1917; Khosla and Lochan 1992; Nand et al. 1996). These pathways imply that a population subjected to crowded housing conditions and tuberculosis in its youth should exhibit elevated rates of cancer and stroke in adulthood, and that a population exposed to tainted drinking water and typhoid fever in its youth should exhibit elevated rates of heart disease and kidney failure in adulthood. Although previous studies try to link measures of material want early in life with 
later life health outcomes, the results of these efforts have been mixed and call for further research (Dedman et al. 2001; Ness et al. 2005).

In the analysis that follows, cities in turn-of-the-century America serve as a laboratory in which to explore the hypothesis that crowed housing conditions and impure water supplies have lingering health effects. This period in American history affords an almost ideal setting

for this experiment. As explained below, during the late-nineteenth and early-twentieth century, American cities were moving from a high-mortality environment where infectious diseases were the leading causes of death, to a low-mortality environment where chronic and age-related diseases such as cancer and heart disease were the leading causes of death. Focusing on time periods within this transition makes it comparatively easy to disentangle the effects of prior disease exposure from contemporaneous exposure. Moreover, while one might question the exogeneity of the mortality transition, evidence presented below suggests that it is appropriate to treat it as such. The specific disease pathways mentioned above-tuberculosis leads to cancer and stroke; typhoid leads to heart and kidney disease-are particularly relevant in this regard. So too is the broader historical literature on the sources of mortality change in urban areas.

\section{Estimating Strategy}

\section{A. Empirical Model}

The estimating strategy employed here involves regressing mortality rates from agerelated pathologies against lagged and contemporaneous measures of deprivation and deprivation-related disease. More formally, variants on the following generic model will be 
estimated:

$$
y_{\mathrm{it}}=\alpha+\beta_{1} x_{\mathrm{it}}+\delta_{1} x_{\mathrm{i}(\mathrm{t}-\mathrm{k})}+\gamma y_{\mathrm{i}(\mathrm{t}-\mathrm{k})}+Z_{\mathrm{it}} \beta_{2}+Z_{\mathrm{i}(\mathrm{t}-\mathrm{k})} \delta_{2}+\epsilon_{\mathrm{it} \prime}
$$

where $y_{\mathrm{it}}$ is the mortality rate from cancer, heart disease, or kidney disease in city $i$ in year $t ; x_{\mathrm{it}}$ is a measure of deprivation (such as persons per dwelling) or a deprivation-related disease (such as tuberculosis or typhoid fever) in city $i$ in year $t ; x_{\mathrm{i}(\mathrm{t}-\mathrm{k})}$ is the measure of deprivation or deprivation-related disease in city $i$ in year $t-k ; y_{\mathrm{i}(t-k)}$ is the lagged value of the dependent variable, or more precisely, the mortality rate from cancer, heart disease, or kidney disease in city $i$ in year $t-k$; $Z_{\mathrm{it}}$ is a vector of contemporaneous control variables, such as the population level and the city's illiteracy rate in city $i$ in year $t ; Z_{\mathrm{i}(\mathrm{t}-\mathrm{k})}$ is a vector of control variables in city $i$ in year $t-k$; and $\epsilon_{\mathrm{it}}$ is a random error term.

If deprivation and deprivation-related diseases early in life adversely affected later-life health outcomes, one expects the lagged measures of deprivation and disease to be correlated with age-related pathologies, even after controlling for the contemporaneous measures of deprivation and disease. Within this econometric framework, the contemporaneous measures of deprivation and disease $\left(x_{\mathrm{it}}\right)$ and the lagged value of the dependent variable $\left(y_{\mathrm{i}(\mathrm{t}-\mathrm{k})}\right)$ will capture, at least partly, any unobserved heterogeneity that might otherwise confound the estimated relationship between the lagged explanatory variables and the dependent variable. Previous studies of the effects of prior disease on current populations generally do not adequately control for the contemporaneous disease environment, and therefore tend to overstate the effects of prior disease (Ben-Shlomo and Smith 1991). In addition, it is possible to assess the effects of unobserved heterogeneity by examining correlations between variables 
that should, in theory, exhibit no correlation. For example, there is no scientific evidence to suggest that prior and acute exposure to typhoid fever increases an individual's risk for stroke or most types of cancer. In light of this, if one observes lagged typhoid rates in year $t-k$ influencing stroke or cancer rates in year $t$, there is reason to believe that the correlation is driven by some unobserved factor.

In equation (1), the variable of primary interest is $x_{\mathrm{i}(\mathrm{t-k})}$, the lagged measure of deprivation or deprivation-related disease. Figure 1 depicts three possible relationships between $x_{\mathrm{i}(\mathrm{t}-\mathrm{k})}$ and the dependent variable, $y_{\mathrm{it}}$. Line (A) illustrates the relationship if early-life exposure to deprivation and deprivation-related disease has lasting effects on human health. This relationship implies that cities with relatively poor water supplies or crowded housing in the year $t-k$, have elevated rates of cancer, heart disease, and kidney disease in year $t$. Line (B) illustrates a competing and equally plausible hypothesis. Cities with relatively poor water supplies or crowded housing in year $t-k$ have low rates of cancer, heart disease, or kidney disease in year $t$. This outcome would result if deprivation in year $t-k$ induce rates of infectious disease that are so high that only the most robust and healthy individuals can survive to year $t$. Put another way, infections in the early period kill the population that would die from cancer, heart disease, and kidney disease in the later period. Line (C) illustrates an intermediate and non-linear relationship. This relationship implies that only cities with extremely high rates of deprivation and deprivation-related disease in period $t-k$ would give rise to the censoring process embodied in line (B). 


\section{B. The Data and Some Preliminary Observations}

To implement the strategy described above, a sample of 110 American cities is compiled and observed over two time periods, 1915 (year $t$ ) and 1900 (year $t-k$ ). For each city in the sample, information regarding mortality rates from infectious and age-related diseases are gathered from the 1900 and 1915 volumes of the United States Mortality Statistics. Data on the population and housing density are taken from various Census volumes. Table 1 reports descriptive statistics for the sample in both 1900 and 1915. Death rates are reported as deaths per 100,000 persons. The mean total mortality rate for 1900 is 1,812.0; the mean rate for 1915 is 1,451.7. The smallest city in the sample is Pawtucket, RI, with a population of 11,523 in 1900 ; the largest city is New York with a population of 3,437,202 in 1900. The median city is Manchester, NH, with a population of 56,987 in 1900.

Table 1 reveals two patterns of interest. First, the total mortality rate fell by roughly 20 percent between 1900 and 1915. This decline was part of rapid downward trend in urban mortality that began after 1880 and ended sometime around 1940. Demographers and economic historians refer to this decline as the urban mortality transition (Haines 2001). Second, as cities moved from high to low mortality regimes, chronic diseases and diseases of old age replaced infectious diseases as the leading causes of death. This change can be seen in the statistics reported in table 1. Between 1900 and 1915, the death rates from cancer, heart disease, and kidney disease rose by 50,6, and 38 percent, respectively. Over the same period, the death rates from tuberculosis and typhoid fever fell by 33 and 66 percent, respectively.

The hypothesis that early life deprivation has lasting health effects suggests that one 
should observe persistence in mortality levels across cities, despite the changing disease profile. Cities that had relatively high infectious disease rates of during the high-mortality regime, would have also had relatively high rates of cancer, heart disease, and other agingrelated pathologies during the early stages of the low-mortality regime. Evidence of such persistence can be seen in figure 2, which plots the total mortality rate in 1915 against the mortality rate in 1900. The total mortality rate in 1900 explains more than 30 percent of the mortality rate in 1915. Although the sources of such persistence were probably manifold, one possible explanation is that the infectious diseases that dominated the urban landscape during the late 1800 s had lingering effects on the individuals who survived.

Trying to identify the long term of early life deprivation and disease would be problematic if one did not focus on this particular period in American demographic history. If one looked at earlier (later) eras so that infectious disease rates remained high (low) over the entire study period, it would be difficult to disentangle the effects of prior disease exposure on current health from the effects of contemporaneous disease exposure. Furthermore, the precise timing of the urban mortality transition differed across cities. In some cities the transition began during the late 1800s; in others, the transition did not begin until the early 1900s. Hence by focusing on repeated cross sections during the transition period broadly construed, one can obtain greater inter-city variation in mortality rates and disease profiles than could be realized by looking at periods when all cities were operating in either high or low-mortality regimes. 


\section{C. Was the Urban Mortality Transition Unrelated to Prior Disease Rates?}

If the factors that initiated the mortality transition were somehow correlated with mortality from age-related diseases this would undermine the assumption, implicit thus far, that the urban mortality transition was unrelated to prior infectious disease rates. Consider, in particular, the possibility that the mortality transition began only after local governments enacted some policy $P$. Assume that policy $P$ was designed to eradicate infectious diseases; that the policy succeeded in that end; and that the cities most likely to enact $P$ were those with the highest death rates from infectious diseases in 1900. Assume further that policy $P$, while it reduced infectious disease rates in the short term, had undesirable secondary effects that undermined long-term health prospects. Although this scenario is predicated on a long list of assumptions, it is not implausible, and if true, might bias the estimated coefficients on the lagged measures of deprivation and deprivation-related disease. The relevant questions, therefore, are twofold. First, can one identify any historical policies that might have conformed to such a scenario? Second, if so, what estimating strategies might be employed to address the potential relationship between the mortality transition and lagged disease rates?

Regarding the first question, demographers and economic historians emphasize the following three forces as having set the urban mortality transition in motion: the discovery and dissemination of the germ theory of disease (Mokyr 2000); sustained economic growth, which resulted in higher wages, better living conditions, and increased caloric intake and improved nutrition (Fogel and Costa 1997; McKeown 1976); and large public health initiatives in urban sanitation and disease prevention, such as the installation of public water and sewer 
systems (Meeker 1974; Szreter 1988, 1997). It is unlikely that the discovery and dissemination of the germ theory disease could have generated an outcome consistent with that implied by the discussion of policy $P$. The discovery that diseases like cholera, typhoid, and tuberculosis were caused by specific bacterial agents, as opposed to some miasmatic poison floating in the air, was mainly the result of scientific inquiry and experimentation (Melosi 2000, pp. 60-61). Furthermore, while the dissemination of the germ theory induced behavioral changes at the household level such as keeping a cleaner house and washing one's hands more frequently (Mokyr 2000), it is difficult to see how these changes would have undermined the long-term health of their practitioners.

Economic growth appears a more likely avenue. One could imagine, for example, that while economic growth might have promoted better housing and nutrition, which helped reduce infectious disease rates in the short term, such growth also generated externalities that undermined health in the long term, particularly in the form of increased cancer rates (Szreter 1997). A crude but suggestive piece of evidence in favor of this proposition is that while Massacusetts, arguably the most rapidly growing and industrializing state in America, lead the country in terms of eradicating infectious diseases, it had the highest cancer rates of any state during the late nineteenth century (U.S. Census Bureau 1880). Proponents of growthlead mortality declines, however, generally portray the mechanisms as operating on a national or supranational scale, and at least implicitly, seem to suggest that regional differences within nations would not have been sufficient to generate the outcomes implied by the discussion of policy $P$ above (Fogel and Costa 1997; McKeown 1976). To the extent that labor and food 
markets were integrated within and between industrializing nations, the emphasis on national and supranational change would seem appropriate. The available evidence suggests extensive international and national market integration by the late-nineteenth and early-twentieth century (O’Rourke and Williamson 1999).

Nevertheless, it is a simple matter to directly control for differences in growth across cities. If differences economic growth rates across urban areas is what drives the correlation between age-related disease rates and lagged infectious disease rates then that correlation should vanish, or at least become much smaller, once one adds measures of population change to the regressions. In addition, the econometric results presented later in this paper indicate that prior exposure to deprivation and deprivation-related disease works through specific disease pathways that are scientifically plausible. There is no evidence that prior deprivation affects age-related diseases in surprising or theoretically remote ways. For example, the results below indicate that populations exposed to crowded living conditions and tuberculosis early in life exhibit higher rates of cancer later in life. This pattern is sensible in light of modern medical research showing that a history of tuberculosis is a predisposing factor for cancer (e.g., Wu et al. 1995). The results, however, also indicate that prior exposure to crowded housing and tuberculosis had no impact on rates of kidney disease later in life. This pattern is also sensible in light of modern medical research which contains no evidence of a systematic relationship between prior tuberculosis infections and kidney disease. It is not all clear how an interpretative framework that relies solely on differences in economic growth could account for the physiological specificity with which early-life deprivation appears to 
affect later-life health outcomes.

The most promising candidate to assume the role of policy $P$ is the introduction of urban water and sewer systems, and related attempts to filter and purify public water supplies. Municipal governments improved public water supplies mainly to eradicate diseases like infant diarrhea and typhoid fever, and such improvements had a large effect on the health of urban populations. In Chicago, IL, for example, improvements in the city's water supply account for roughly 40 percent of the mortality decline observed between 1850 and 1925 (Ferrie and Troesken 2005), and the experience of Chicago was not unique (Cutler and Miller 2005). Perhaps efforts to improve public water supplies helped eliminate a broad swathe of infectious diseases, but also inadvertently exposed urban dwellers to chemicals that increased the incidence of cancer, heart disease, and kidney disease later in life.

There are at least two pieces of evidence that support the idea that water treatment processes during the early 1900s might have impaired long-term health. First, the chemistry of water treatment is complex, as are the potential health effects of alternative treatment processes (Booker 2000; Foss-Mollan 2001, pp. 168-75). Only recently have scientists and policymakers come to appreciate this complexity. In 1900, the engineers who operated water treatment facilities were almost exclusively concerned with eradicating bacterial pathogens; they were much less concerned, if they were concerned at all, about inorganic water constituents and their potential effects on human health (Melosi 2000). Second, recent research in public and environmental health suggests that water can affect human health in a myriad of hitherto unappreciated ways. For example, water hardness is correlated with 
cardiovascular disease and the source of this correlation remains a mystery (Sauvant and Pepin 2002); heavy metals corroded from the interior of water distribution pipes, previously considered an unimportant health risk, have been shown to adversely affect both the young and old (Troesken 2006); and the by products of water treatment techniques used to destroy organic pathogens like typhoid and cryptosporidium has been shown to increase the risk of cancer and adverse pregnancy outcomes (Boorman et al. 1999; Bove et al. 2002).

The possible connection between water treatment and age-related pathologies can be explored through remedial steps. For example, one might imagine that the cities that were the most aggressive in treating their water supplies with potentially carcinogenic chemicals were those with the highest typhoid rates in 1900. If so, one should observe a strong correlation between cancer rates in 1915 and typhoid rates in 1900, despite the fact that there is no medical evidence that prior exposure to an acute typhoid infection increases a person's risk of developing cancer later in life. ${ }^{1}$ An alternative would be to ask if the water treatment processes introduced after 1900 might account for relationships involving tuberculosis, crowded housing, and subsequent cancer rates.

Another candidate for policy $P$ is the introduction of vaccines and antibiotics to

${ }^{1}$ There is evidence that typhoid carriers, who are chronically exposed to the typhoid bacilli, face a higher risk of urinary and gall bladder cancer. There are, however, three reasons to believe that this effect would not be sufficiently large to influence the estimation strategy outlined above. First, less than 5 percent of all individuals exposed to typhoid ever become carriers (Bhan et al. 2005). Second, today as in the past, gall bladder and urinary cancer are relatively uncommon forms of cancer, with the former accounting for less than 1 percent of all cases and the latter accounting for less than 10 percent (Edwards et al. 2005). Third, individuals exposed to acute infections, who constitute more than 90 percent of all typhoid victims, do not suffer from elevated rates of cancer later in life (Caygill et al. 1994). 
combat infectious diseases. Most demographic and economic historians, however, do not believe improved medical therapies played a significant role in the mortality transition. Consider the fall in tuberculosis and typhoid rates highlighted in table 1. Although Koch isolated the tuberculosis bacillus during the late nineteenth century, the first effective vaccine was not introduced until 1921. Antibiotic treatments for tuberculosis were not introduced until the 1940s. These changes come too late to explain even part of the decline in mortality shown in table 1, which focuses on the period 1900 to 1915 (Johnston 1993).

In the case of typhoid, Almroth Wright developed an effective typhoid vaccine around 1900. Employing dead bacteria to induce an immune response, the vaccine had a protective effect of about 75 percent. While the vaccine could be produced cheaply and easily, it was costly to store and administer. The vaccine was given through three shots with a hypodermic needle, each shot ten days apart. The vaccine also frequently caused adverse reactions, including high fever, soreness, nausea, vomiting, and headaches. Developed in England, the Wright vaccine did not gain popularity in the United States until World War I, when the American high command ordered mandatory vaccination for all soldiers. ${ }^{2}$ As for clinical treatments, these did not come on the scene until fairly late. Not until 1948, when doctors started giving typhoid victims the antibiotic chloramphenicol, did the medical community

\footnotetext{
${ }^{2}$ In part because of these reactions and the vaccine's limited effectiveness, the Secretary of the Connecticut State Board of Health argued in 1913 that: "It is not to be expected . . that typhoid vaccination will ever be used as is smallpox vaccination and depended upon for the eradication of typhoid, nor should it be. For that purpose we continue to depend on, and strive for, pure water, pure food, proper sewerage disposal, and other hygienic measures." See Townsend (1913).
} 
develop effective treatments for typhoid fever (LeBaron and Taylor 1993).

\section{Two Infectious Diseases}

This section reviews the etiology of two infectious diseases, tuberculosis and typhoid fever. The central messages of this discussion are twofold. First, both tuberculosis and typhoid are positively correlated with poverty and material deprivation. In the case of tuberculosis, poor diet and crowded housing conditions are strong predictors of the incidence of the disease. In the case of typhoid fever, impure water and inadequate sewerage are the main determinants of disease rates. Second, both tuberculosis and typhoid have long-lasting effects on human health, so that exposure to either disease increases the risk of various pathologies later in life.

\section{A. Tuberculosis}

Although tuberculosis was endemic in much of the ancient world, it did not become a prominent cause of death in Europe and North America until the eighteenth and nineteenth centuries, when rapid industrialization and urbanization created the population densities necessary for the disease to proliferate. Today, about one-third of the world's population is infected with tuberculosis. With nine million new cases arising every year, there are two to three million deaths from tuberculosis annually. Depending on the region, estimated case fatality rates range from 10 to 50 percent. The geographic variation in the incidence of tuberculosis suggests the disease is correlated with poverty and underdevelopment. For example, in Indonesia and Zimbabwe, 49 and 64 percent of the population, respectively, is infected with tuberculosis. In contrast, in Europe less than 20 percent of the population is 
infected, with the heaviest burden of the disease located in the poorest and least developed regions. In the United States, 7 percent of the population is infected (Dye et al. 1999; Johnston 1993).

Tuberculosis is caused by the bacillus, Mycobacterium tuberculosis. Once they enter the body, tubercle bacilli have no fixed or easily defined incubation and illness period. They can result in a quick and acute infection that kills the victim in a few weeks, or they can lie dormant for years until an individual's resistance falls. Once the infection becomes active, however, it usually takes months and sometimes years before the disease culminates in either recovery or death. Although tuberculosis can infect almost any part of the body, it is most commonly associated with the lungs and a persistent and violent cough. In advanced cases, patients will sometimes cough up blood hemorrhaged in the lungs, but more frequently, coughing produces only blood-streaked sputum. Aside from frequent coughing, other symptoms of an active tuberculosis infection include anorexia, weight loss, fatigue, low-grade anxiety, irregular menstruation in women, muscle aches, sweating, fever, and intermittent chills. Because tuberculosis often produces mild symptoms that mimic the common cold or the flu, historically many individuals recovered from the disease without ever realizing they had it. In contrast to many other infectious diseases, exposure to tuberculosis early in life confers no immunity or protection against later life infections (Johnston 1993).

As for the long-term effects of tuberculosis on human health, the current medical literature focuses mainly on cancer. Prior lung disease is generally recognized as a risk factor for lung cancer (Ernster 1996). For example, in a study of nearly 2,000 non-smoking American 
women, Wu et al. (1995) find that a history of lung disease such as tuberculosis or pneumonia increases the risk of developing lung cancer by 56 percent. More recently, Tocque et al. (2005) followed a cohort of 439 tuberculosis patients over an eight year period. Of these patients, twenty four (28 percent) died from cancer within the study period. This implies that TB patients are 30 times more likely than the general population to die of lung cancer within eight years of developing active cases of tuberculosis. There are also reports that a history of tuberculosis increases the risk of prostate cancer and brain tumors (Ilic et al. 1996; Mills et al. 1989; Sidney et al. 1991). Although the precise mechanisms through which tuberculosis gives rise to cancer are not yet clear, recent research focuses on the immunological processes involved in combating both cancer and tuberculosis and higher protein expression in certain genes after tuberculosis infection (Cocito and Maes 1998; Song et al. 2005).

Beyond cancer, there is evidence indicating that infectious agents, particularly Chlamydia pneumoniae, play a role in the pathogenesis of atherosclerosis, myocardial infarction, and stroke (Nieto 1998; Macko et al. 1996). The evidence linking inflammatory infections like tuberculosis and influenza to strokes later in life appears particularly strong, and for certain populations, respiratory infections could increase the risk of stroke by a factor of 4 (Paganini-Hill et al. 2002). It has been shown, for example, that AIDS patients, who are especially vulnerable to tuberculosis and other infections, have an elevated risk of stroke (Cole et al. 2003). Along the same lines, Grau et al. (2005) show that regular influenza vaccination reduces the risk of stroke.

A variety of host factors shape individual vulnerability to tuberculosis. Infants, 
children, adolescents, and the elderly are more vulnerable to active infection than are young adults and the middle aged. Below the age of thirty, women are at greater risk from dying from tuberculosis than men, while after thirty, the male mortality rate exceeds the female rate (Johnston 1993). Genetic factors heavily influence the ability of individuals and groups to withstand tuberculosis and help explain why only 10 percent of those infected with TB ever develop the active disease (Ottenhoff et al. 2005). This genetic component raises the possibility that repeated exposure has given some ethnic groups a heightened level of immunity to tuberculosis. For example, there is evidence to suggest that Jews are more resistant to the disease than other groups because of their long history of living in urban areas (Johnston 1993). Individuals with compromised immune systems are particularly vulnerable to tuberculosis, and the disease is pervasive among individuals with HIV and AIDS (MohleBoetani et al. 2002). Relatedly, animal experiments indicate that stress undermines immune function and impairs the body's ability to fight off tuberculosis (El-Lethey et al. 2003).

Nutritional status has long been recognized as an important determinant of TBmortality (Macallan 1999). During the early twentieth century, there emerged a series of studies showing that protein-rich diets hastened recovery and promoted immunity against tuberculosis (Lange and Simmond 1923; Krause and Willis 1919; Zueblin 1924). More recent studies indicate that deficiencies in vitamin D predispose individuals to severe cases of tuberculosis (Wilkinson et al. 2000), and suggest that high cholesterol diets can hasten recovery from the disease (Pérez-Guzmán et al. 2005). Large-scale epidemiological studies indicate that populations with low serum cholesterol levels have elevated rates of tuberculosis and 
tuberculosis mortality (Kozarevic et al. 1981). Overall nutrition and body mass are important because tuberculosis induces wasting and anorexia. Individuals with higher body mass, therefore, are in a better position to survive the disease. Beyond this, it is well known that alcoholics are more susceptible to tuberculosis than the general population. This heightened susceptibility appears to be related to altered T cell modulation in the alcoholic (Li et al. 1998).

The two environmental factors that have the greatest impact on tuberculosis are working and housing conditions. Individuals working in dusty trades tend to have much higher rates of tuberculosis than the general population. For example, the rate of tuberculosis among coal miners in northern Spain is three times greater than the rate among non-coal miners in the same region (Mosquera et al. 1994). Similarly, gold miners in South Africa and foundry workers in Denmark who are exposed to silica dust have elevated rates of tuberculosis (Sherson and Lander 1990; Hnizdo and Murray 1998). Overcrowded and poorlyventilated housing has long been recognized as facilitating the transmission of tuberculosis. Crowding matters because when an infected individual coughs or sneezes, the residue hangs in the air, and can be easily inhaled by those close by. The connection between crowded housing and tuberculosis is among the most robust epidemiological associations ever discovered, and has been confirmed repeatedly in modern, case-controlled studies (Johnston 1993; Reinhard et al. 1997; Elender et al. 1998).

\section{B. Typhoid Fever}

Typhoid fever is caused by Salmonella typhi, a bacterium which survives only in human hosts and lives in the intestinal tract. People typically contract typhoid by drinking water 
tainted with human waste. Historically, a common transmission might have gone like this. The family of a typhoid victim dumped the patient's waste into a cesspool or privy vault. If the vault was too shallow or had leaks, it seeped into underground water sources. In turn, if these water sources were not adequately filtered, people who drew their water from them contracted typhoid. A related mode of transmission occurred when surface privies were not screened. With open privies, flies would interact with the pathogens contained in human wastes and then transfer the germs to the kitchens of neighboring homes. Fly-transmitted infections appear to have been common in the American South, where the climate was conducive to the proliferation of insects. Although tainted drinking water and inadequate sewerage are the most frequent modes of transmission, other vectors include: shellfish from polluted waters; milk handled by typhoid infected individuals; vegetables washed with tainted water; and direct infections from typhoid carriers. (Budd 1877; Whipple 1908; Terry 1911).

To the extent poverty is correlated with poor sanitation and health practices, typhoid is also positively correlated with poverty. For example, in the U.S., Europe, and Japan today, the annual death rate from typhoid is less 1 death per 100,000 persons, while in lesser-developed areas, such as Africa and southeast Asia, annual death rates range from 500 to 1,000 (Crump et al. 2004). Conversely, there is evidence that improvements in public water supplies (which eventually eradicated typhoid fever in American cities) benefitted poor socioeconomic groups disproportionately. In the typical American city, water filtration reduced black typhoid rates by 53 percent, but white typhoid rates by only 16 percent (Troesken 2004). This pattern 
supports the idea that disadvantaged socioeconomic groups were relatively ineffective in preventing typhoid fever through private means. It also supports the idea that the disadvantaged bore the brunt of disease in the absence of filtered and universally distributed water supplies.

Once they enter the body, typhoid bacilli have a one to three week incubation period. During incubation, an infected individual experiences mild fatigue, loss of appetite, and minor muscle aches. After incubation, more severe symptoms develop, including, chills, coated tongue, nose bleeds, coughing, insomnia, nausea, and diarrhea. At its early stages, typhoid's symptoms often resemble those of respiratory diseases and pneumonia is often present. In nearly all cases, typhoid victims develop a severe fever with body temperatures reaching as high as $105^{\circ}$ Fahrenheit. A week or so after incubation, rose-colored spots sometimes appear on the patient's abdomen. Three weeks after incubation, the disease is at its worst. The patient is delirious, emaciated, and often has blood-tinged stools. Historically, perhaps as many as one in five typhoid victims experienced a gastrointestinal hemorrhage. Internal hemorrhaging results when typhoid perforates the intestinal wall, and frequently continues on to attack the kidneys and liver (Bhan et al. 2005; LeBaron and Taylor 1993).

Typhoid fever has diffuse effects, adversely impacting many physiological systems, including the heart and respiratory system, the liver and kidneys, and the neurological system. Khosla (1981) reports that 12 percent of typhoid patients studied during the midtwentieth century experienced some sort of cardiac event while fighting off the disease. A study of 65 lethal cases of typhoid fever among Russian soldiers between 1980 and 1986 finds 
that 85 percent of the population experienced myocarditis, and in 14 percent of the cases acute heart failure was the proximate cause of death (Bobin et al. 1993). Animal experiments reveal similar evidence (Sen et al. 1987). As for typhoid's impact on respiratory function, recent autopsies of typhoid victims reveal evidence consistent with respiratory distress syndrome (Azad et al. 1997). The aforementioned study of Russian soldiers suggests that about 75 percent of all typhoid victims develop pneumonia, and that pneumonia is the proximate cause of death in 20 percent of the cases (Bobin et al. 1993). The claim that typhoid adversely affects respiratory function receives support from Costa (2000), who shows that exposure to typhoid increases the risk of respiratory problems later in life by more than 50 percent.

In a recent paper with the apt title, "The Liver in Typhoid Fever: Always Affected, Not Just a Complication," Morgenstern and Hayes (1991) show that 90 percent of all typhoid cases have some degree of liver involvement, ranging from biochemical abnormalities to overt hepatitis- about 5 percent of all typhoid victims develop hepatitis. Kidney problems are also common, ranging from swelling and high protein levels in the urine, to full-blown nephritis. Studies of current populations suggest that at least 10 to 15 percent of typhoid sufferers experience a significant abnormality in kidney function. In another study, 79 percent of all typhoid victims experienced symptoms consistent with urinary tract infections (Adu et al. 1975; Khosla and Lochan 1992). Today, complications with the kidney and liver can be managed through dialysis and drug treatment, limiting the long-term damage to these vital organs. However, among historical populations, typhoid was allowed to run its course and it seems likely that the disease would have left the kidneys and liver irreparably compromised 
for a large portion of the population that survived the short term effects of the disease.

The high fever associated with typhoid is so severe that between 35 to 85 percent of all victims experience neurological complications. These complications include abnormal behavior, babbling speech, nervous tremors, severe confusion, and visual hallucinations (30 to 70 percent of all cases); some type of swelling or inflamation of the brain or spinal chord (5 to 10 percent of all cases); and acute schizophrenia or psychosis (1 to 2 percent of all cases). Autopsies of people who have been killed by typhoid reveal diffuse damage to neurons, softening of the brain's vascular system, the formation of abscesses on the brain, and discharges of pus in the brain and meninges (Ali et al. 1997). If, however, the patient survives all of this, the fever begins to fall off and a long period of recovery sets in. It can take as long as four months to fully recover. Surprisingly, given the breadth and severity of typhoid's symptoms, more than 90 percent of its victims survived historically, and today, with the aid of antibiotics, more than 99 percent of typhoid patients survive (Bhan et al. 2005; LeBaron and Taylor 1993).

That typhoid killed only 5 to 10 percent of its victims might lead one to wonder just how significant this disease could have been for human health and longevity. But typhoid's low case fatality rate understates its true impact, because when the disease did not kill quickly and directly, it killed slowly and indirectly. Consider, for example, how typhoid affected the cardiovascular system over the long term. Using a sample of nearly 30,000 Union Army veterans, Costa (2000) shows that those recruits who fell victim to typhoid during the Civil War had a 25 percent higher risk of heart trouble forty years later. In a turn-of-the-century 
study, Thayer (1904) followed 182 typhoid survivors over a thirteen-year period. He found that typhoid survivors had elevated pulse rates, high blood pressure, enlarged hearts, and suffered from cardiac murmurs more frequently than the control population. More recently, fifty adult patients with typhoid fever were given daily ECGs and electrolyte assessments to evaluate cardiac status. Of these patients, 29 (58 percent) exhibited ECG or enzyme changes, and 17 (34 percent) exhibited both ECG and enzyme changes. Based on these findings, the authors of this study conclude that "definite injury to the heart occurs during typhoid fever" (Nand et al. 1996).

More general evidence regarding typhoid's lingering health effects comes from a study conducted by Dublin (1915). A statistician for the Metropolitan Life Insurance Company, Dublin followed 1,574 typhoid survivors over a three year period. Comparing the mortality rates of typhoid survivors to the mortality rates of similarly-aged persons in the general population, he found that typhoid survivors were, on average, 3 times more likely to have died than the general population in the first year after recovery, and typhoid survivors were 2 times more likely to have died than the general population in the second year after recovery. The two biggest killers of the typhoid survivors were tuberculosis (39 percent of all deaths) and heart failure (23 percent). Other prominent killers included kidney failure (8 percent) and pneumonia (7 percent).

\section{Results}

Before turning to the formal regression results, consider the patterns exhibited in figures 3, 4, and 5. Taken together, these three figures suggest that cities with crowded 
housing in the year 1900 increased the incidence of tuberculosis during the same period, and in turn, because prior exposure to TB is a risk factor for cancer, these same cities had elevated rates of cancer fifteen years later. Using the city-level data described above, figure 3 plots tuberculosis rates in 1900 against persons per dwelling in 1900. A trend line is also plotted $\left(R^{2}\right.$ $=.091$ ). Consistent with much other research, the patterns here suggest a strong positive correlation between tuberculosis and crowded housing. Figure 4 plots cancer rates in 1915 against persons per dwelling in 1900. Two fitted lines are also plotted. One fitted line is based on a simple linear regression model that excludes four cities with unusually crowded housing conditions $\left(R^{2}=.049\right)$; the other is based on a model that includes the square of persons-perdwelling $\left(R^{2}=.051\right)$. These data indicate that in cities that had fewer than 9.2 persons per dwelling, there is a positive and statistically significant relationship between crowded housing conditions in 1900 and cancer rates fifteen years later. Figure 5 plots cancer rates in 1915 against tuberculosis rates in 1900. The trend line is based on a regression that includes the square of the tuberculosis rate in 1900 , as well as the level $\left(R^{2}=.098\right)$. These data mirror those shown in figure 4, and suggest that cancer rates in 1915 were positively correlated with tuberculosis rates in 1900, below some threshold level of tuberculosis.

Table 2 reports the formal regression results. Regression (1) suggests that even after controlling for lagged cancer rates and for persons-per-dwelling in 1915, there exists a parabolic relationship between persons per dwelling in 1900 and the cancer rate in 1915. The fit, however, is noisy and not as strong as when tuberculosis rates are used directly. Regression (2) shows that even after controlling for lagged cancer rates and for the 
tuberculosis rate in 1915, there exists a parabolic relationship between the tuberculosis rate in 1900 and the cancer rate in 1915. The estimates from regression (2) imply that had tuberculosis been eradicated in 1900, the death rate from cancer in 1915 would have been 32 percent lower than it otherwise was. Figure 6 plots the relationship between the 1900-tuberculosis rate and the 1915-cancer rate implied by the estimates in regression (2). The vertical lines at 348 and 432 indicate the $95^{\text {th }}$ and $99^{\text {th }}$ percentiles, respectively, for the tuberculosis rate in 1900 . In light of the distribution of tuberculosis rates in 1900, the estimated relationship between the lagged tuberculosis rate and the cancer rate in 1915 suggests that for all but a handful of cities with unusually high rates of $\mathrm{TB}$, there was a strong positive relationship between cancer and prior tuberculosis rates.

Regressions (3) and (4) explore the relationship between stroke and prior exposure to poor housing and tuberculosis. There is not a statistically significant relationship between stroke in 1915 and housing density in 1900 (see regression 3). However, there is a strong and statistically significant correlation between stroke in 1915 and the tuberculosis rate in 1900. The estimates from regression (4) imply that had tuberculosis been eradicated in 1900, the death rate from stroke in 1915 would have been 32 percent lower than it otherwise was. Figure 7 plots the relationship between the 1900-tuberculosis rate and the 1915-stroke rate implied by the estimates in regression (4). As before, the vertical lines indicate the $95^{\text {th }}$ and $99^{\text {th }}$ percentiles for the tuberculosis rate in 1900. In light of the distribution, the estimated relationship between the lagged tuberculosis rate and the stroke rate in 1915 suggests that for all but a handful of cities with unusually high rates of $\mathrm{TB}$, there was a strong positive 
relationship between stroke and prior tuberculosis rates. The parabolic relationship between the 1900-tuberculosis rate and the 1915-stroke rate is sufficiently strong that it can be observed in the raw data as well. This is shown in figure 8, which plots the 1915-stroke rate against the 1900-tuberculosis rate. A non-linear trend line is also plotted $\left(R^{2}=.044\right)$.

Regressions (1)-(4) are consistent with the existing medical literature, which indicates that there are specific physiological pathways through which exposure to tuberculosis at an early life stage increases the risk of cancer and stroke at a later life stage. Nevertheless, it is possible that regressions (1)-(4) are picking up the effects of some unobserved process, and not the effects of prior exposure to crowded housing conditions and tuberculosis. To explore this possibility further, regressions (5) and (6) identify the extent to which prior exposure to tuberculosis increases the risk of kidney disease later in life. Because there exists no scientific or medical evidence to suggest that a history of tuberculosis is a risk factor for kidney disease, any correlation between the death rate from kidney disease in 1915 and the death rate from tuberculosis in 1900 would raise questions about what drives the correlation between cancer/stroke and prior tuberculosis rates. However, regressions (5) and (6) indicate that there is no such correlation.

To the extent that tuberculosis was associated with crowded housing and poor nutrition, the results above suggest that exposure to inadequate housing and diet at an early life stage increased the risk of cancer and stroke at a later life stage. A related hypothesis is that exposure to polluted water and unsanitary sewage disposal also has lingering health effects. This hypothesis can be tested by looking at the relationship between typhoid fever 
and various age-related pathologies. As explained above, impure water supplies and substandard sewerage systems affected poor socioeconomic groups disproportionately and resulted in high rates of typhoid fever. Furthermore, typhoid fever had a low case fatality rate, had diffuse health effects, and damaged critical organs, particularly the heart and kidneys. Hence, if exposure to impure water and inadequate sewage disposal at an early life stage increased the risk of disease at a later life stage, one expects to observe a strong and positive correlation between heart and kidney disease in 1915 and typhoid in 1900.

Figures 9 and 10, which plot the death rate from heart and kidney disease in 1915 and against the death rate from typhoid fever in 1900, support the hypothesis that exposure to tainted drinking water and substandard sewerage had lingering health effects. In particular, for death rates from typhoid fever in 1900 that range from 10 to 60 deaths per 100,000 persons, figure 9 shows that the death rate from heart disease in 1915 rises from around 140 to more than 160. After the death rate from typhoid in 1900 reaches 70, a censoring process sets in and typhoid begins to kill off individuals who would have otherwise died from heart disease later in life. It is notable, however, that most cities had death rates below this threshold. Figure 10 reveals the same basic pattern for kidney disease. Typhoid rates between 10 and 70 are associated increases in the death rate from kidney disease fifteen years later, while typhoid rates greater than 70 are associated with declining rates of kidney disease in later years.

Table 3 reports the results of three regressions. Regression (1) supports the findings presented in figure 8 regarding typhoid fever and heart disease. After controlling for the contemporaneous typhoid rate and the lagged death rate from heart disease, the typhoid rate 
in 1900 is related in a parabolic fashion to the death rate from heart disease in 1915. Moreover, the coefficient estimates suggest that the lagged typhoid rate had a large effect on heart disease. In particular, if urban governments in 1900 could have eradicated typhoid fever, the death rate from heart disease in 1915 would have been reduced by 21 percent. Regression (2) identifies the effects of early-life exposure to typhoid on the death rate from kidney disease in later life. After controlling for the contemporaneous typhoid rate and the lagged death rate from kidney disease, the typhoid rate in 1900 is related in a parabolic fashion to the death rate from kidney disease in 1915. The coefficient estimates suggest that typhoid had a large and adverse effect on long-term kidney function. If typhoid fever had been eradicated in 1900 (through aggressive investment in urban water and sewer systems), the death rate from kidney disease in 1915 would have been reduced by 23 percent.

Regressions (3) and (4) explore the possibility that regressions (1) and (2) yield biased results because of unobserved heterogeneity. It explores this possibility by identifying the correlations between cancer and typhoid fever; and between stroke and typhoid. As explained above, there is no evidence that exposure to typhoid at an earlier life stage increases the risk of stroke or most forms of cancer at a later life stage. (The only exception to this is the very small proportion of the exposed population that become typhoid carries. Typhoid carriers have an elevated risk of bladder cancer, a relatively uncommon form of cancer.) If the correlation between heart/kidney disease and lagged typhoid fever rates is driven by unobserved heterogeneity, one might expect to observe the same correlation between cancer/stroke and lagged typhoid rates even though there is no scientific evidence to suggest such a relationship. 
The results of regression (3), however, do not indicate that cancer is related to lagged typhoid rates in the same way as heart and kidney disease. On the contrary, the exact opposite pattern obtains. Below some threshold, increasing typhoid rates in 1900 are associated with falling cancer rates in 1915. This is consistent with the idea that typhoid was killing off individuals who would have otherwise died from cancer later in life. The results in regression (4), moreover, indicate that there is no systematic correlation between the death rate from stroke in 1915 and the death rate from typhoid fever in 1900.

\section{Conclusions}

The results above are consistent with the hypothesis that deprivation early in life can have lingering physiological effects. In particular, the results suggest that crowded housing conditions in early life facilitate the spread of tuberculosis, which in turn, increases the risk of cancer and stroke later in life. The lingering effects of crowded housing and tuberculosis appear to have been large. In the typical city, eradicating tuberculosis in 1900 would have reduced the death rates from cancer and stroke in 1915 by 32 percent. Similarly, drinking impure water in early life raises the likelihood that one will be infected with typhoid fever, which in turn, increases the risk of heart and kidney disease later in life. Again, the lingering effects appear to have been large. In the typical city, eradicating typhoid fever in 1900 would have reduced the death rate from heart disease by 21 percent, and the death rate from kidney disease by 23 percent. These results are obtained after including controls for the contemporaneous disease environment, and after including lagged values of the dependent variable and the overall disease environment. 


\section{References}

Adu, D., Y. Anim-Addo, A.K. Foli, E.D. Yeboah, J.K. Quartey. 1975. “Acute Renal Failure and Typhoid Fever." Ghana Medical Journal, 14:172-74.

Ali, Gazanfar, Samia Rashid, M.A. Kamli, Parvez A. Shah, and G.Q. Allaqaband. 1997. "Spectrum of Neuropsychiatric Complications in 791 Cases of Typhoid Fever." Tropical Medicine and International Health, 2:314-18.

Alison, W.P. 1842. "On the Destitution and Mortality in Some Large Towns in Scotland," Journal of the Statistical Society of London, 5:289-92.

Appleby, Andrew B. 1979. “Diet: Sources: Problems, Possibilities," in Health, Medicine, and Mortality in the Sixteenth Century. Charles Webster, editor. Cambridge.

Azad, A.K., R. Islam, M.A. Salam, A.N. Alam, M. Islam, and T. Butler. 1997. “Comparison of Clinical Features and Pathologic Findings in Fatal Cases of Typhoid Fever During the Initial and Later Stages of the Disease," American Journal of Tropical Medicine and Hygiene, 56:490-93.

Barker, D.J.P. 1992. Fetal and Infant Origins of Adult Disease. London: BMJ Publishing Group.

Barker, D.J.P. 1994. Mothers, Babies, and Disease Later in Life. London: BMJ Publishing Group.

Ben-Schlomo, Y., and G.D. Smith. 1991. “Deprivation in Infancy or in Adult Life: Which is More Important for Mortality Risk?" Lancet, 337:530-34.

Bengtsson, T., and M. Lindstrom. 2000. “Childhood Misery and Disease in Later Life: the Effects on Mortality in Old Age of Hazards Experienced in Early Life, southern Sweden, 1760-1894," Population Studies, 54:263-77.

Bhan, M.K., Rajiv Bahl, and Shinjini Bhatnagar. 2005. "Typhoid and Paratyphoid Fever," Lancet, 366:749-62.

Bobin, A.N., N.D. Klochkov, and N.V. Bogomolova. 1993. "Complications and the Proximate Cause of Death in Typhoid," Voenno-Meditsinkii Zhurnal, 1:49-52.

Booker, Susan. 2000. “NTP Taps Disinfection By-Products for Study,” Environmental Health Perspectives, 108:A64-A67. 
Boorman, G.A., V. Dellarco, J.K. Dunnick, et al. 1999. “Drinking Water Disinfection ByProducts: Review and Approach to Toxicity Evaluation," Environmental Health Perspectives, 107:207-217.

Bove, F., Y. Shim, and P. Zeitz. 2002. “Drinking Water Contaminants and Adverse Pregnancy Outcomes: A Review," Environmental Health Perspectives, 110:61-74.

Britton, Warwick J., and Umainthan Palendira. 2003. “Improving Vaccines against Tuberculosis," Immunology and Cell Biology, 81:34-45.

Budd, William. 1877. "Typhoid Fever: Its Nature, Mode of Spreading, and Prevention." Reprinted in American Journal of Public Health, 8:610-12.

Caygill, C.P.J., M.J. Hill, M. Braddick, et al. 1994. “Cancer in Chronic Typhoid and Paratyphoid Carriers," Lancet, 343:83-84.

Cocita, C., and H. Maes. 1998. "Immunological Relatedness of the Protective Mechanisms against Tuberculosis and Cancer," European Journal of Clinical Investigation, 28:1-12.

Cole, John W., Amelia N. Pinto, J. Richard Hebel, et al. 2003. "Acquired Immunodeficiency Syndrome and the Risk of Stroke," Stroke, 35:51-56.

Costa, Dora L. 2000. “Understanding the Twentieth-Century Decline in Chronic Conditions Among Older Men." Demography, 37:53-72.

Crump, J.A., S.P. Luby, and E.D. Mintz. 2004. “The Global Burden of Typhoid Fever,” Bulletin of the World Health Organization, 82:346-53.

Curschmann, H. 1901. Typhoid Fever and Typhus Fever. Philadelphia: W.B. Saunders and Company.

Cutler, David M., and Grant Miller. 2004. “The Role of Public Health Improvements in Health Advances: The $20^{\text {th }}$ Century United States." NBER working paper \#10511.

Dedman, D.J., D. Gunnell, G. Davey Smith, et al. 2001. “Childhood Housing Conditions and Later Mortality in the Boyd Orr Cohort," Journal of Epidemiology and Community Health, 55:10-15.

Dorling, D., R. Mitchell, M. Shaw, et al. 2000. “The Ghosts of Christmas Past: Health Effects of Poverty in London in 1896 and 1991," British Medical Journal, 321:1547-51. 
Dublin, Louis I. 1915. “Typhoid Fever and Its Sequelae." American Journal of Public Health, 5:20-27.

Dye, Christopher, Suzanne Scheele, Paul Dolin, et al. 1999. “Global Burden of Tuberculosis: Estimated Incidence, Prevalence, and Mortality by Country," Journal of the American Medical Association, 282:677-86.

Edwards, Brenda K., Martin L. Brown, Phyllis A. Wingo, Holly L. Howe, et al. 2005. “Annual Report to the Nation on the Status of Cancer, 1975-2005, Featuring Population Based Trends in Cancer Treatment," Journal of the National Cancer Institute, 97:1407-26.

Elender, F., G. Bentham, and I. Langford. 1998. "Tuberculosis Mortality in England and Wales during 1982-1992: Its Association with Poverty, Ethnicity, and AIDS," Social Science and Medicine, 46:673-81.

El-Lethey, H., B. Huber-Eicher, T.W. Jungi. 2003. “Exploration of Stress Induced Immunosuppression in Chickens Reveals Both Stress-Resistant and Stress-Susceptible Antigen Responses," Veterinary Immunology and Immunopathology, 95:91-101.

Ernster, V.L. 1996. “Female Lung Cancer," Annual Review of Public Health, 17:97-114.

Ferrie, Joseph P., and Werner Troesken. 2005. “Death and the City: Chicago's Mortality Transition, 1857-1925." Working Paper. National Bureau of Economic Research. Cambridge, MA.

Fogel, Robert W., and Dora L. Costa. 1997. "A Theory of Technophysio Evolution, with Some Implications for Forecasting Population, Health Care Costs, and Pension Costs," Demography, 34:49-66.

Foss-Mollan, K. 2001. Hard Water: Politics and Water Supply in Milwaukee, 1870-1995. West Lafayette, IN: Purdue University Press.

Grau, A.J., B. Fischer, C. Barth, et al. 2005. “Influenza Vaccination is Associated with a Reduced Risk of Stroke," Stroke, 36:1501-06.

Griffin, Daniel. 1841. "An Enquiry into the Mortality Occurring Among the Poor of the City of Limerick," Journal of the Statistical Society of London, 3:305-30.

Haines, Michael R. 1995. “Socio-economic Differentials in Infant and Child Mortality during the Mortality Decline: England and Wales, 1890-1911," Population Studies, 49:297-315. 
Haines, Michael R. 2001. "The Urban Mortality Transition in the United States, 1800-1940." Historical Paper No. 134. National Bureau of Economic Research. (A shorter version of this paper also appears in the journal Annales de Demographie Historique.)

Hare, Hobart Amory, and E.J.G. Beardsley. 1909. The Medical Complications Accidents and Sequels of Typhoid Fever and the Other Exanthemata. Philadelphia: Lea \& Febiger.

Hnizdo, E., and J. Murray. 1998. "Risk of Pulmonary Tuberculosis Relative to Silicosis and Exposure to Silica Dust in South African Gold Miners," Occupational and Environmental Medicine, 55:496-505.

Horrocks, Thomas A. 1995. “'The Poor Man's Riches, The Rich Man's Bliss': Regimen, Reform, and the 'Journal of Health', 1829-1833," Proceedings of the American Philosophical Society, 139:115-34.

Ilic, M., H. Vlajinac, and J. Marinkovic. 1996. "Case-Control Study of Risk Factors for Prostate Cancer," British Journal of Cancer, 74:1682-86.

Johnston, William D. 1993. "Tuberculosis," in The Cambridge World History of Disease. Kenneth Kiple, editor. New York: Cambridge University Press.

Khosla, S.N. 1981. "The Heart in Enteric (Typhoid) Fever." Journal of Tropical Medicine and Hygiene, 84:125-31.

Khosla, S.N., and R. Lochan. 1992. "Renal Dysfunction in Enteric Fever." Journal of the Association of Physicians of India, 39:382-84.

Kozarevic, D., D. McGee, N. Vojvodic, T. Gordon, Z. Racic, W. Zukel, and T. Dawber. 1981. "Serum Cholesterol and Mortality: the Yugoslavia Cardiovascular Study," American Journal of Epidemiology, 114:21-28.

Krause, A.K., and H.S. Willis. 1919. "Experiments on the Influence of Protein Intoxication on Tuberculosis Infection in Guinea Pigs," American Review of Tuberculosis, 3:153-65.

Lange, Linda B., and Nina Simmond. 1923-24. "Experimental Tuberculosis in Rats in Varied Diets; Protein and Salt Factors," American Review of Tuberculosis, 7:49-59.

LeBaron, Charles W., and David W. Taylor. 1993. "Typhoid Fever," in The Cambridge World History of Disease. Kenneth Kiple, editor. New York: Cambridge University Press.

Leon, David A., and George Davey Smith. 2000. “Infant Mortality, Stomach Cancer, Stroke, and Coronary Heart Disease: Ecological Analysis," British Medical Journal, 320:1705-06. 
Li, X., C.J. Grossman, C.L. Mendenhall, et al. 1998. “Host Responses to Mycobacterial Infection in the Alcoholic Rat: Male and Female Dimorphism," Alcohol, 16:207-12.

Macallan, D.C. 1999. "Malnutrition in Tuberculosis," Diagnostic Microbiology and Infectious Disease, 34:153-57.

Macleod, John, George Davey Smith, Chris Metcalf, et al. 2005. “Is Subjective Social Status a More Important Determinant of Health Than Objective Social Status? Evidence from a Prospective Observational Study of Scottish Men," Social Science and Medicine, 61:191629.

Macko, Richard F., Sebastian F. Ameriso, Robert Barndt, et al. 1996. “Precipitants of Brain Infarction: Rolse of Preceding Infection/Inflammation and Recent Psychological Stress," Stroke, 27:1999-2004.

Mathal, Elizabeth, T. Jacob John, Mallika Rani, et al. 1995. "Significance of Salmonella Typhi Bacteriuria." Journal of Clinical Microbiology, 33:1791-92.

Meeker, Edward. 1974. “The Social Rate of Return on Investment in Public Health, 18801910," Journal of Economic History, 34:392-421.

Melosi, Martin V. 2000. The Sanitary City: Urban Infrastructure in America from Colonial Times to the Present. Baltimore: The Johns Hopkins University Press.

Mills, P.K., S. Preston-Martin, J.F. Annegers, et al. 1989. “Risk Factors for Tumors of the Brain and Cranial Meninges in Seventh-Day Adventists," Neuroepidemiology, 8:266-75.

McKeown, Thomas J. 1976. The Modern Rise of Population. New York: Academic Press.

Mohle-Boetani, Janet C., Vanessa Miguelino, Daniel H. Dewsnup, et al. 2002. “Tuberculosis Outbreak in a Housing Unit for Human Immunodeficiency Virus - Infected Patients in a Correctional Facility: Transmission Risk Factors and Effective Outbreak Control," Clinical Infectious Diseases, 34:668-76.

Mokyr, Joel. 2000. “Why 'More Work for Mother?' Knowledge and Household Behavior, 1870-1945," Journal of Economic History, 60:1-41.

Morgenstern, R. and P.C. Hayes. 1991. “The Liver in Typhoid Fever: Always Affected, Not Just a Complication." American Journal of Gastroenterology, 86:1235-39.

Mosquera, J.A., L. Rodrigo, and Z.F. González. 1994. “The Evolution of Tuberculosis in Coal Miners in Asturias, Northern Spain," European Journal of Epidemiology, 10:291-97. 
McSherry, G., and E. Connor. 1993. “Current Epidemiology of Tuberculosis," Pediatric Annals, 22:600-04.

Nand, N., M. Sharma, M. Bhutani, G.P. Singh, and V.K. Sharma. 1996. “Cardiac Status in Typhoid Fever," Angiology, 47:1095-100.

Neito, F.J. 1998. "Infections and Atherosclerosis: New Clues from an Old Hypothesis," American Journal of Epidemiology, 148:937-48.

Ness, A.R., M. Maynard, S. Frankel, et al. 2005. “Diet in Childhood and Adult Cardiovascular and All Cause Mortality: the Boyd Orr Cohort," Heart, 91:894-98.

O'Rourke, Kevin H., and Jeffrey G. Williamson. 1999. Globalization and History: The Evolution of a Nineteenth-Century Atlantic Economy. Cambridge: MIT Press.

Ottenhoff, T.H., F.A. Verreck, M.A. Hoeve, et al. 2005. “Control of Human Host Immunity to Mycobacteria," Tuberculosis, 85:53-64.

Pananini-Hill, A., E. Lorano, G. Fischberg, et al. 2003. “Infection and Risk of Ischemic Stroke: Differences Among Stroke Subtypes," Stroke, 34:452-57.

Pérez-Guzmán, C., M.H. Vargas, F. Quiñonez, N. Bazavilvazo, and A. Aguilar. 2005. “A Cholesterol-Rich Diet Accelerates Bacteriologic Sterilization in Pulmonary Tuberculosis," Chest, 127:643-51.

Pollock, Linda. 1990. "Embarking on a Rough Passage: The Experience of Pregnancy in Early Modern Society," in Women as Mothers in Pre-Industrial England. Valerie Fildes (editor). London.

Reinhard, C., W.S. Paul, and J.B. McAuley. 1997. "Epidemiology of Pediatric Tuberculosis in Chicago, 1974 to 1994: A Continuing Public Health Problem," American Journal of Medical Sciences, 313:336-40.

Sauvant, M.P., and D. Pepin. 2002. “Drinking Water and Cardiovascular Disease," Food and Chemical Toxicology, 40:1311-25.

Sen, P., T. Khanna, P. Mahajan, S.K. Bhattacharya, and K. Saha. 1987. "Effect of Typhoid Endotoxin on Cardiovascular System of Some Animals," Indian Journal of Experimental Biology, 25:181-86. 
Sherson, D., and F.J. Lander. 1990. "Morbidity of Pulmonary Tuberculosis Among Silcotic and Nonsilicotic Foundry Workers in Denmark," Occupational Medicine, 32:110-13.

Sidney, S., C. Quesenberry, M.C. Sadler, et al. 1991. "Risk Factors for surgically Treated Benign Prostatic Hyperplasia in a Prepaid Health Care Plan," Urology, 38:13-19.

Song, L., W. Yan, T. Zhao, M. Deng, S. Song, J. Zhang, and M. Zhu. 2005. “Mycobacterium Tuberculosis Infection and FHIT Gene Alterations in Lung Cancer," Cancer Letters, 219:155-62.

Stevenson, T.H.C. 1921. "The Incidence of Mortality Upon the Rich and Poor Districts of Paris and London," Journal of the Royal Statistical Society, 84:90-99.

Sykes, W.H. 1850. "Statistical Account of the Labouring Population Inhabiting the Buildings at St. Pancras, Erected by the Metropolitan Society for Improving the Dwellings of the Poor," Journal of the Statistical Society of London, 13:46-61.

Szreter, Simon. 1988. “The Importance of Social Intervention in Britain's Mortality Decline c. 1850-1915: A Reinterpretation of the Role of Public Health," Social History of Medicine, $1: 1-37$.

Szreter, Simon. 1997. “Economic Growth, Dispruption, Deprivation, Disease, and Death: On the Importance of the Politics of Public Health for Development," Population and Development Review, 23:693-728.

Terry, C.E. 1911. "Extermination of the House Fly in Cities, Its Necessity and Possibility," American Journal of Public Health, 2:14-22.

Thayer, W.S. 1904. “On the Late Effects of Typhoid Fever on the Heart and Vessels: A Clinical Study," American Journal of Medical Sciences, 127:391-422.

Tocque, K., R.P. Convrey, M.A. Bellis, N.J. Beeching, and P.D. Davies. 2005. "Elevated Mortality Following Diagnosis with a Treatable Disease: Tuberculosis," International Journal of Tuberculosis and Lung Disease, 9:797-802.

Townsend, Joseph H. 1913. "Anti-Typhoid Vaccination," American Journal of Public Health, 3:993-98.

Troesken, Werner. 2004. Water, Race, and Disease. Cambridge: MIT Press.

Troesken, Werner. 2006. The Great Lead Water Pipe Disaster. Cambridge: MIT Press. 
Whipple, George C. 1908. Typhoid Fever: Its Causation, Transmission, and Prevention. New York: John Wiley and Sons.

Wilkinson, Robert J., Martin Llewelyn, Zahra Toossi, et al. 2000. “Influence of Vitamin D Deficiency and Vitamin D Receptor Polymorphisms on Tuberculosis among Gujarati Asians in West London: A Case-Control Study," Lancet, 355:618-21.

Wu, A.H., E.T. Fontham, P. Reynolds, R.S. Greenberg, P. Buffler, J. Liff, P. Boyd, B.E. Henderson, and P. Correa. 1995. "Previous Lung Disease and Risk of Lung Cancer among Lifetime Nonsmoking Women in the United States," American Journal of Epidemiology, 141:1023-32.

Zueblin, E. 1924. "Protein and Vitamin Therapy in Tuberculosis," International Journal of Surgery, 37:293, 342, and 428. 


\section{Table 1. Descriptive Statistics}

\begin{tabular}{|c|c|c|c|c|c|c|c|c|}
\hline \multirow[b]{2}{*}{ Variable } & \multicolumn{4}{|c|}{1900} & \multicolumn{4}{|c|}{1915} \\
\hline & mean & std dev & $\min$ & $\max$ & mean & std dev & $\min$ & $\max$ \\
\hline Total mortality rate $\mathrm{a}^{\mathrm{a}}$ & 1812.0 & 410.0 & 746.0 & 3100.0 & 1451.7 & 295.4 & 744.8 & 2464.9 \\
\hline Cancer mortality rate ${ }^{\mathrm{b}}$ & 60.0 & 16.8 & 21.3 & 117.0 & 89.8 & 22.1 & 38.5 & 160.7 \\
\hline Kidney mortality rate ${ }^{c}$ & 84.9 & 34.8 & 32.4 & 213.2 & 117.3 & 45.2 & 55.8 & 260.0 \\
\hline Heart mortality rate ${ }^{\mathrm{d}}$ & 144.7 & 41.0 & 54.8 & 273.1 & 154.1 & 47.7 & 51.8 & 314.6 \\
\hline Stroke mortality rate ${ }^{\mathrm{e}}$ & 174.8 & 57.5 & 69.8 & 369.1 & 83.4 & 27.7 & 26.1 & 159.7 \\
\hline Tuberculosis mortality rate $\mathrm{f}^{\mathrm{f}}$ & 190.2 & 81.3 & 11.1 & 512.0 & 127.7 & 58.7 & 39.6 & 367.5 \\
\hline Typhoid mortality rate ${ }^{\mathrm{g}}$ & 39.4 & 23.3 & 10.0 & 131.9 & 13.3 & 9.1 & 0.0 & 37.1 \\
\hline Population in 000s & 154.4 & 382.1 & 115.2 & 343.7 & 253.3 & 614.1 & 29.3 & 5620.0 \\
\hline Persons per dwelling & 6.3 & 1.7 & 4.4 & 14.2 & 6.2 & 2.0 & 4.3 & 15.4 \\
\hline Number of observations & \multicolumn{4}{|c|}{110} & \multicolumn{4}{|c|}{110} \\
\hline
\end{tabular}

Notes:

a - Total mortality rate: deaths from all causes per 100,000 persons.

b - Cancer mortality rate: deaths from cancer per 100,000 persons.

c - Kidney mortality rate: deaths from kidney disease per 100,000 persons.

d - Heart mortality rate: deaths from heart disease per 100,000 persons.

e - Stroke mortality rate: deaths from stroke per 100,000 persons.

f - Tuberculosis mortality rate: deaths from tuberculosis per 100,000 persons.

g - Typhoid mortality rate: deaths from typhoid fever per 100,000 persons.

Sources: United States Census, 1900 and 1920 volumes; United States, Mortality Statistics, 1900 and 1915 volumes. 
Table 2. The Lingering Effects of Tuberculosis

\begin{tabular}{|c|c|c|c|c|c|c|}
\hline \multirow[b]{2}{*}{ Variable } & \multicolumn{2}{|c|}{ Cancer, 1915} & \multicolumn{2}{|c|}{ Stroke, 1915} & \multicolumn{2}{|c|}{ Kidney, 1915} \\
\hline & $(1)^{*}$ & $(2)$ & $(3)^{*}$ & $(4)$ & $(5)^{*}$ & (6) \\
\hline $\begin{array}{l}\text { Persons per } \\
\text { dwelling, } 1915\end{array}$ & $\begin{array}{l}-4.98 \\
(9.25)\end{array}$ & $\ldots$ & $\begin{array}{c}11.4 \\
(12.7)\end{array}$ & $\ldots$ & $\begin{array}{c}.435 \\
(15.2)\end{array}$ & $\ldots$ \\
\hline $\begin{array}{l}\text { (Persons per } \\
\quad \text { dwelling, 1915) }\end{array}$ & $\begin{array}{c}.448 \\
(.611)\end{array}$ & . & $\begin{array}{l}-.328 \\
(.830)\end{array}$ & $\ldots$ & $\begin{array}{l}-.510 \\
(1.01)\end{array}$ & \\
\hline $\begin{array}{l}\text { Total mortality } \\
\text { rate, } 1915^{\dagger}\end{array}$ & $\ldots$ & $\begin{array}{l}.058^{\mathrm{a}} \\
(.008)\end{array}$ & $\ldots$ & $\begin{array}{l}.052^{\mathrm{a}} \\
(.011)\end{array}$ & $\ldots$ & $\begin{array}{l}.073^{\mathrm{a}} \\
(.014)\end{array}$ \\
\hline $\begin{array}{l}\text { Tuberculosis rate, } \\
1915\end{array}$ & $\cdots$ & $\begin{array}{l}-.022 \\
(.119)\end{array}$ & $\cdots$ & $\begin{array}{l}-.134 \\
(.164)\end{array}$ & $\ldots$ & $\begin{array}{l}.078 \\
(.209)\end{array}$ \\
\hline $\begin{array}{l}\text { (Tuberculosis rate, } \\
1915)^{2}(000 \mathrm{~s})\end{array}$ & $\ldots$ & $\begin{array}{l}-.107^{\mathrm{c}} \\
(.382)\end{array}$ & $\cdots$ & $\begin{array}{c}.001 \\
(.001)\end{array}$ & $\ldots$ & $\begin{array}{c}.065 \\
(.682)\end{array}$ \\
\hline $\begin{array}{l}\text { Population (000s), } \\
1915\end{array}$ & $\begin{array}{l}.050^{c} \\
(.022)\end{array}$ & $\begin{array}{l}.038^{\mathrm{d}} \\
(.021)\end{array}$ & $\begin{array}{l}-.067^{\mathrm{c}} \\
(.030)\end{array}$ & $\begin{array}{l}-.029 \\
(.029)\end{array}$ & $\begin{array}{l}-.065^{\mathrm{d}} \\
(.038)\end{array}$ & $\begin{array}{l}-.043 \\
(.034)\end{array}$ \\
\hline $\begin{array}{l}\text { Persons per } \\
\text { dwelling, } 1900\end{array}$ & $\begin{array}{l}15.5^{\mathrm{e}} \\
(11.4)\end{array}$ & $\cdots$ & $\begin{array}{l}-8.05 \\
(16.2)\end{array}$ & $\ldots$ & $\begin{array}{l}-21.5 \\
(19.0)\end{array}$ & $\ldots$ \\
\hline $\begin{array}{l}\text { (Persons per } \\
\text { dwelling, 1900) }\end{array}$ & $\begin{array}{l}-1.04^{\mathrm{e}} \\
(.759)\end{array}$ & $\ldots$ & $\begin{array}{c}.014 \\
(1.05)\end{array}$ & $\ldots$ & $\begin{array}{c}1.59 \\
(1.26)\end{array}$ & $\cdots$ \\
\hline $\begin{array}{l}\text { Total mortality } \\
\text { rate, } 1900^{\ddagger}\end{array}$ & $\ldots$ & $\begin{array}{l}-.033^{\mathrm{a}} \\
(.006)\end{array}$ & $\ldots$ & $\begin{array}{l}-.032^{\mathrm{b}} \\
(.010)\end{array}$ & $\ldots$ & $\begin{array}{l}-.017^{\mathrm{e}} \\
(.011)\end{array}$ \\
\hline $\begin{array}{l}\text { Dependent } \\
\text { variable, } 1900^{\S}\end{array}$ & $\begin{array}{l}.480^{\mathrm{a}} \\
(.104)\end{array}$ & $\begin{array}{l}.444^{\mathrm{a}} \\
(.093)\end{array}$ & $\begin{array}{l}.186^{\mathrm{a}} \\
(.043)\end{array}$ & $\begin{array}{l}.237^{\mathrm{a}} \\
(.049)\end{array}$ & $\begin{array}{l}.970^{\mathrm{a}} \\
(.084)\end{array}$ & $\begin{array}{l}.731^{\mathrm{a}} \\
(.093)\end{array}$ \\
\hline $\begin{array}{l}\text { Tuberculosis rate, } \\
1900\end{array}$ & $\ldots$ & $\begin{array}{l}.270^{b} \\
(.089)\end{array}$ & $\ldots$ & $\begin{array}{l}.273^{\mathrm{c}} \\
(.120)\end{array}$ & $\ldots$ & $\begin{array}{l}-.104 \\
(.148)\end{array}$ \\
\hline $\begin{array}{l}\text { (Tuberculosis rate, } \\
1900)^{2} \quad \text { (000s) }\end{array}$ & $\ldots$ & $\begin{array}{l}-.588^{b} \\
(.206)\end{array}$ & $\ldots$ & $\begin{array}{l}-.604^{\mathrm{c}} \\
(.261)\end{array}$ & $\ldots$ & $\begin{array}{c}.305 \\
(.325)\end{array}$ \\
\hline $\begin{array}{l}\text { Population (000s), } \\
1900\end{array}$ & $\begin{array}{l}.078^{\mathrm{c}} \\
(.038)\end{array}$ & $\begin{array}{l}.025^{\mathrm{d}} \\
(.015)\end{array}$ & $\begin{array}{l}.101^{\mathrm{c}} \\
(.049)\end{array}$ & $\begin{array}{c}.039 \\
(.046)\end{array}$ & $\begin{array}{l}.100^{\mathrm{e}} \\
(.061)\end{array}$ & $\begin{array}{c}.062 \\
(.056)\end{array}$ \\
\hline Adjusted $R^{2}$ & .227 & .536 & .289 & .490 & .600 & .672 \\
\hline No. of obs. & 103 & 110 & 103 & 110 & 103 & 110 \\
\hline
\end{tabular}

Notes: continued on next 
Notes to Table 2.

A constant term is included in every regression, but is not reported.

a - significant at the .001 level (two-tailed test).

b - significant at the .010 level (two-tailed test).

${ }^{\mathrm{c}}$ - significant at the .050 level (two-tailed test).

d - significant at the .100 level (two-tailed test).

e - significant at the .100 level (one-tailed test).

† - the total mortality rate in 1915 is measured as deaths per 100,000 persons from all causes except tuberculosis and cancer in regression (2); except tuberculosis and stroke in regression (4); and except tuberculosis and kidney disease in regression (6).

$\ddagger$ - the total mortality rate in 1900 is measured as deaths per 100,000 persons from all causes except tuberculosis and cancer in regression (2); except tuberculosis and stroke in regression (4); and except tuberculosis and kidney disease in regression (6).

$\S$ - the lagged value of the dependent variable refers to death rate from cancer in 1900 in regression (2); the death rate from stroke in 1900 in regression (4); and the death rate from kidney disease in 1900 in regression (6).

* - excludes the following outliers: Quincy, IL; Augusta, GA; Elmira, NY; Auburn, GA; Yonkers, NY; New Britain, CT; Bayonne, NJ; and Passaic, NJ.

Sources: United States, Mortality Statistics, 1900 and 1915 volumes. 
Table 3. The Lingering Effects of Typhoid Fever

\begin{tabular}{lcccc}
\hline & \multicolumn{3}{c}{ Dependent variable, 1915} \\
\cline { 2 - 5 } & Kidney Disease & Heart Disease & Cancer & Stroke \\
Variable & $(1)$ & $(2)$ & $(3)$ & $(4)$ \\
\hline Total mortality & $.074^{\mathrm{a}}$ & $.101^{\mathrm{a}}$ & $.043^{\mathrm{a}}$ & $.044^{\mathrm{a}}$ \\
rate, $1915^{\dagger}$ & $(.012)$ & $(.017)$ & $(.008)$ & $(.010)$ \\
Typhoid rate, 1915 & .827 & .456 & .684 & .399 \\
& $(1.05)$ & $(1.44)$ & $(.727)$ & $(.914)$ \\
(Typhoid rate, & -.024 & -.023 & -.015 & -.029 \\
$1915)^{2}$ & $(.029)$ & $(.040)$ & $(.020)$ & $(.025)$ \\
Population $(000 \mathrm{~s})$, & -.042 & -.053 & $-.052^{\mathrm{c}}$ & $-.037^{\mathrm{e}}$ \\
1915 & $(.032)$ & $(.045)$ & $(.022)$ & $(.028)$ \\
Total mortality & -.009 & $-.039^{\mathrm{a}}$ & $-.027^{\mathrm{a}}$ & $-.030^{\mathrm{a}}$ \\
rate, $1900^{\ddagger}$ & $(.008)$ & $(.012)$ & $(.005)$ & $(.008)$ \\
Dependent & $.742^{\mathrm{a}}$ & $.602^{\mathrm{a}}$ & $.525^{\mathrm{a}}$ & $.273^{\mathrm{a}}$ \\
variable, 1900 & $(.087)$ & $(.091)$ & $(.100)$ & $(.050)$ \\
Typhoid rate, & $1.11^{\mathrm{b}}$ & $.998^{\mathrm{d}}$ & $-.474^{\mathrm{d}}$ & -.202 \\
1900 & $(.378)$ & $(.517)$ & $(.262)$ & $(.358)$ \\
(Typhoid rate, & $-.008^{\mathrm{a}}$ & $-.007^{\mathrm{d}}$ & $.003^{\mathrm{e}}$ & .058 \\
1900) & $(.003)$ & $(.004)$ & $(.002)$ & $(.287)$ \\
Population $(000 \mathrm{~s})$, & .061 & .090 & .083 & .050 \\
1900 & $(.052)$ & $(.072)$ & $(.036)$ & $(.045)$ \\
Adjusted $R^{2}$ & & & & \\
No. of obs. & .698 & .496 & .402 & .397 \\
\hline & 110 & 110 & 110 & 110 \\
\hline
\end{tabular}

Notes: continued on next page. 
Notes to Table 3.

A constant term is included in every regression, but is not reported.

a - significant at the .001 level (two-tailed test).

b - significant at the .010 level (two-tailed test).

${ }^{\mathrm{c}}$ - significant at the .050 level (two-tailed test).

d - significant at the .100 level (two-tailed test).

e - significant at the .100 level (one-tailed test).

† - the total mortality rate in 1915 is measured as deaths per 100,000 persons from all causes except typhoid and kidney disease in regression (1); except typhoid and heart disease in regression (2); except typhoid and cancer in regression (3); and except typhoid and stroke in regression (4).

$\ddagger$ - the total mortality rate in 1900 is measured as deaths per 100,000 persons from all causes except typhoid and kidney disease in regression (1); except typhoid and heart disease in regression (2); except typhoid and cancer in regression (3); and except typhoid and stroke in regression (4).

$\S$ - the lagged value of the dependent variable refers to death rate from kidney disease in 1900 in regression (1); the death rate from heart disease in 1900 in regression (2); the death rate from cancer in 1900 in regression (3); and the death rate from stroke in 1900 in regression (4).

Sources: United States Mortality Statistics, 1900 and 1915 volumes. 


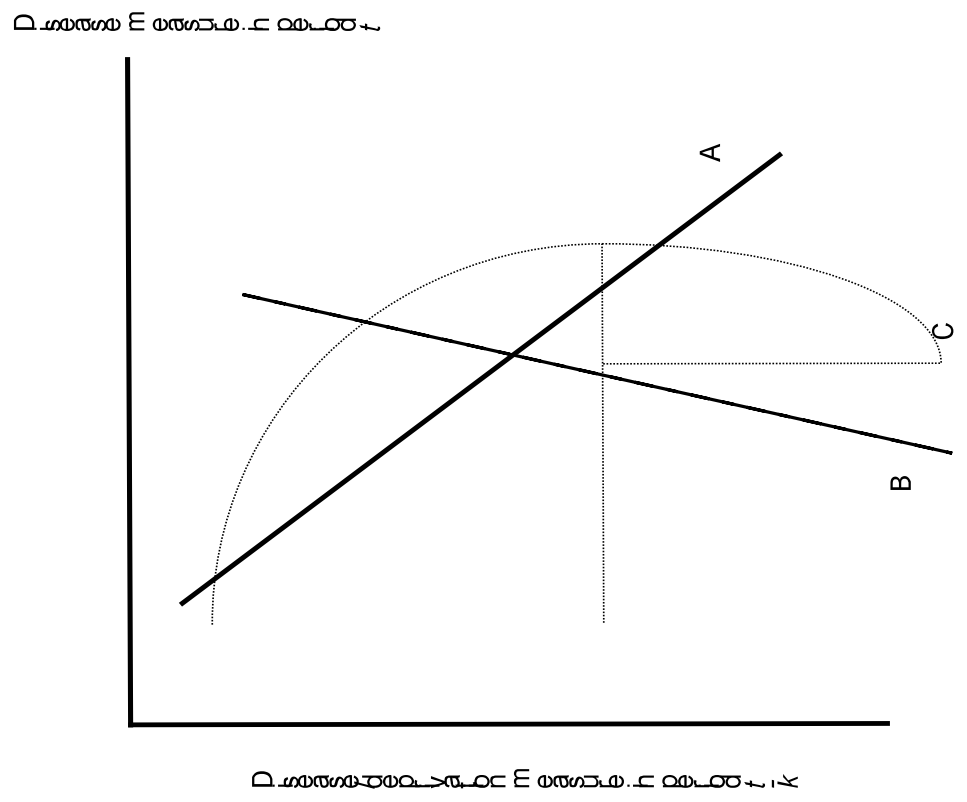

Figure 1. Possible Relationships Between Lagged and Contemporaneous Disease Rates Source: see text. 


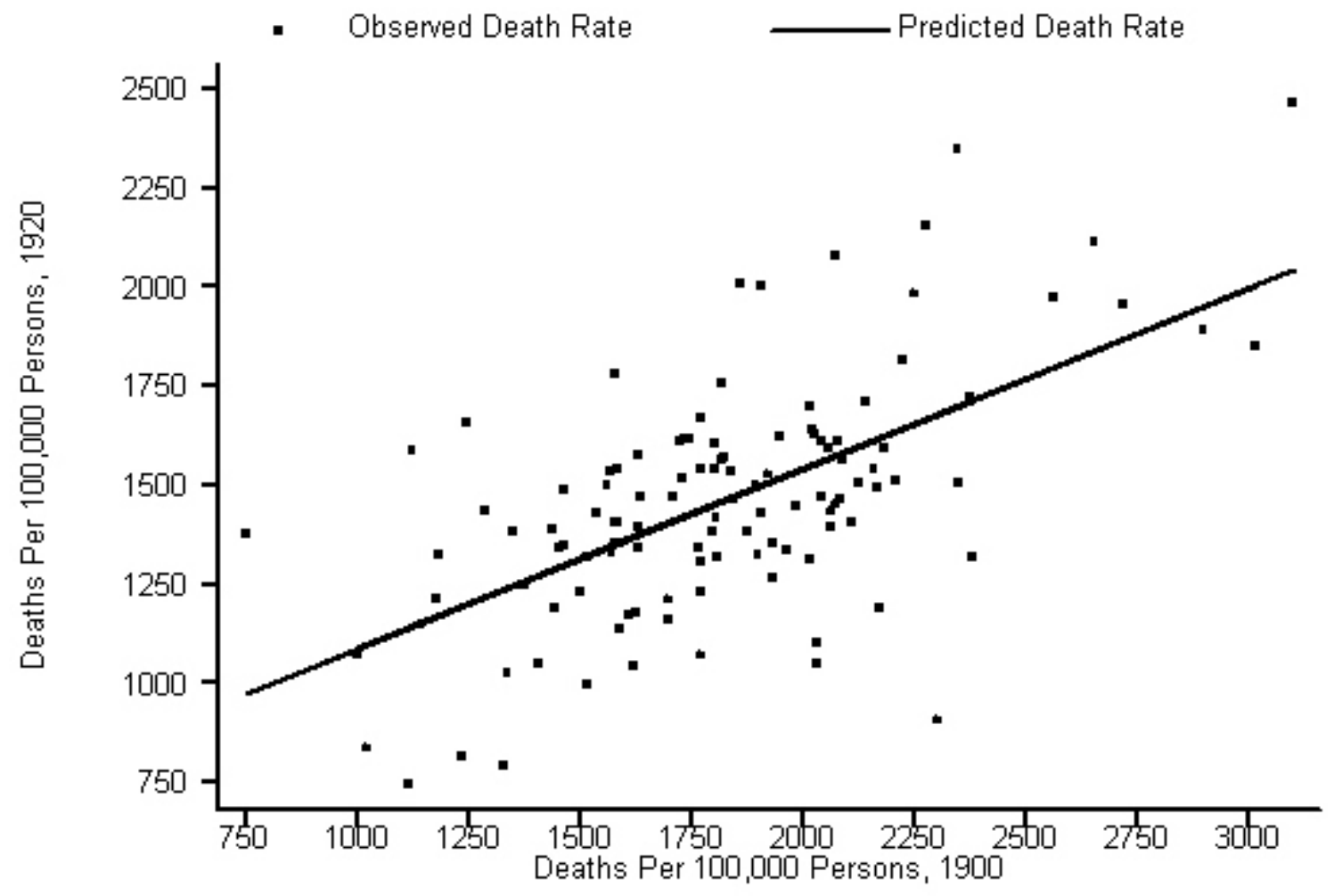

Figure 2. Persistence in Mortality Rates: 1900-1915

Sources: United States, Mortality Statistics, 1900 and 1915 volumes. 


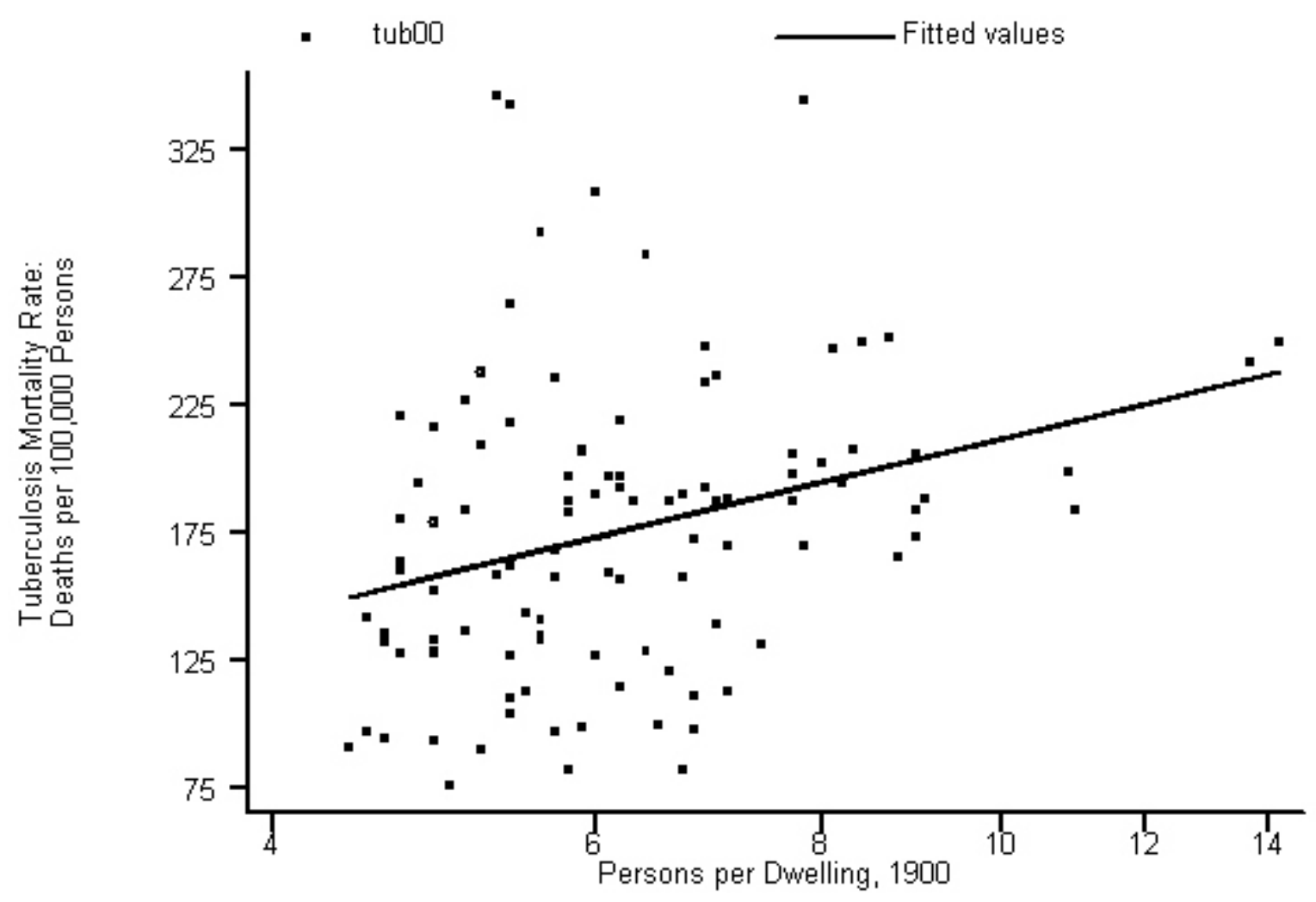

Figure 3. Tuberculosis and Housing Density, 1900

Sources: United States Census, 1900, and United States Mortality Statistics, 1900. 


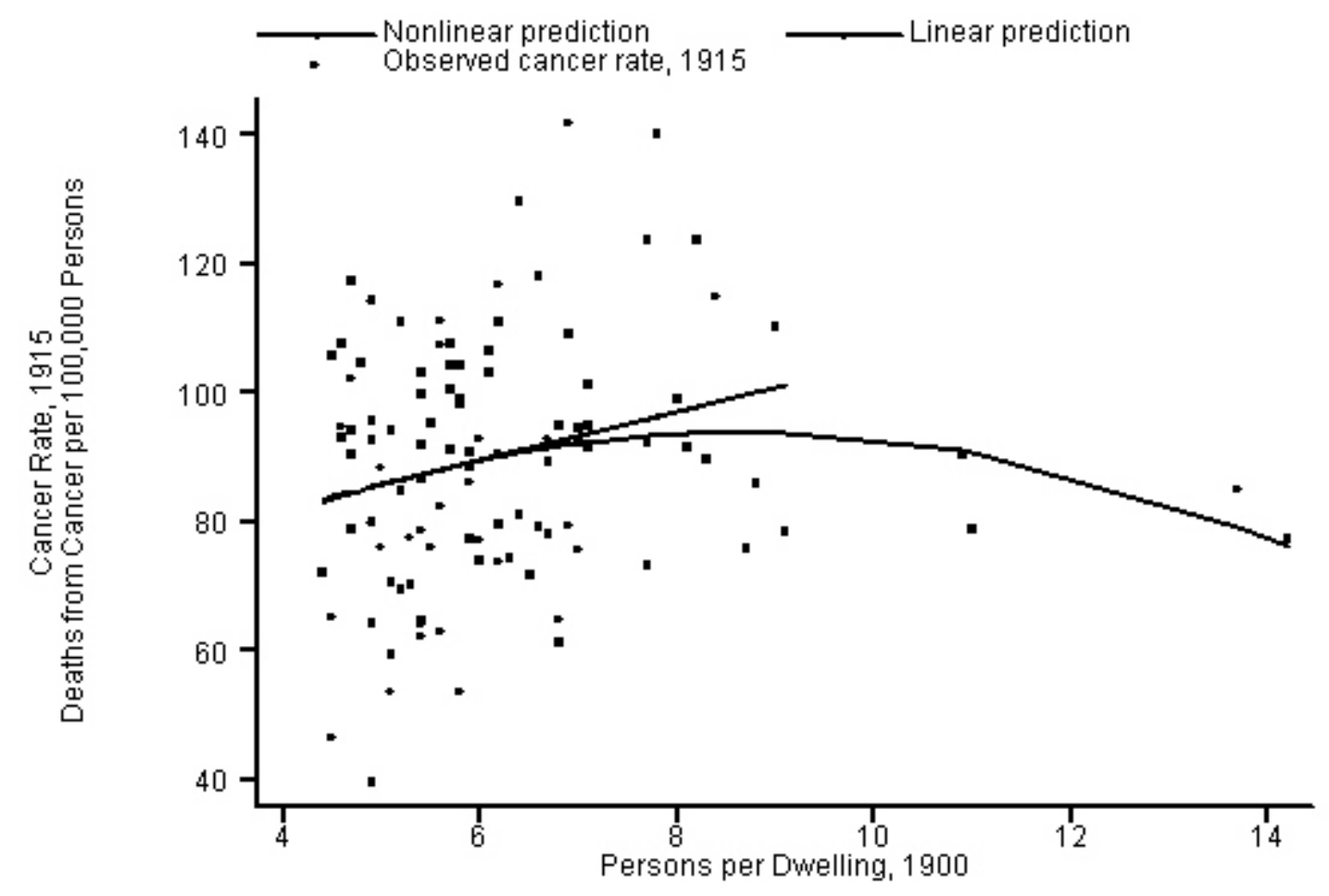

Figure 4. Cancer in 1915 and Housing Density in 1900

Sources: United States Census, 1900, and United States Mortality Statistics, 1915. 


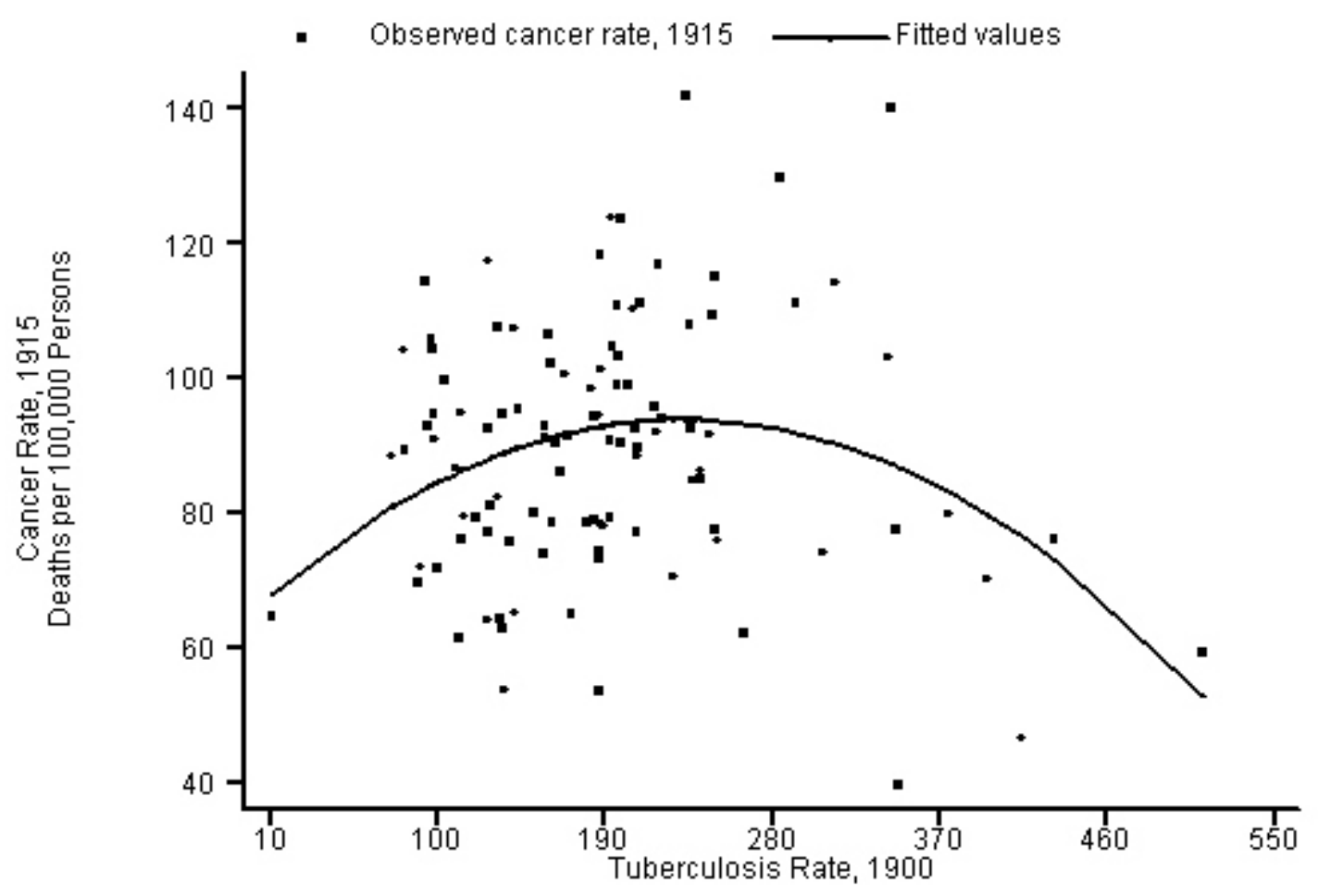

Figure 5. Cancer in 1915 and Tuberculosis in 1900

Sources: United States, Mortality Statistics, 1900 and 1915. 


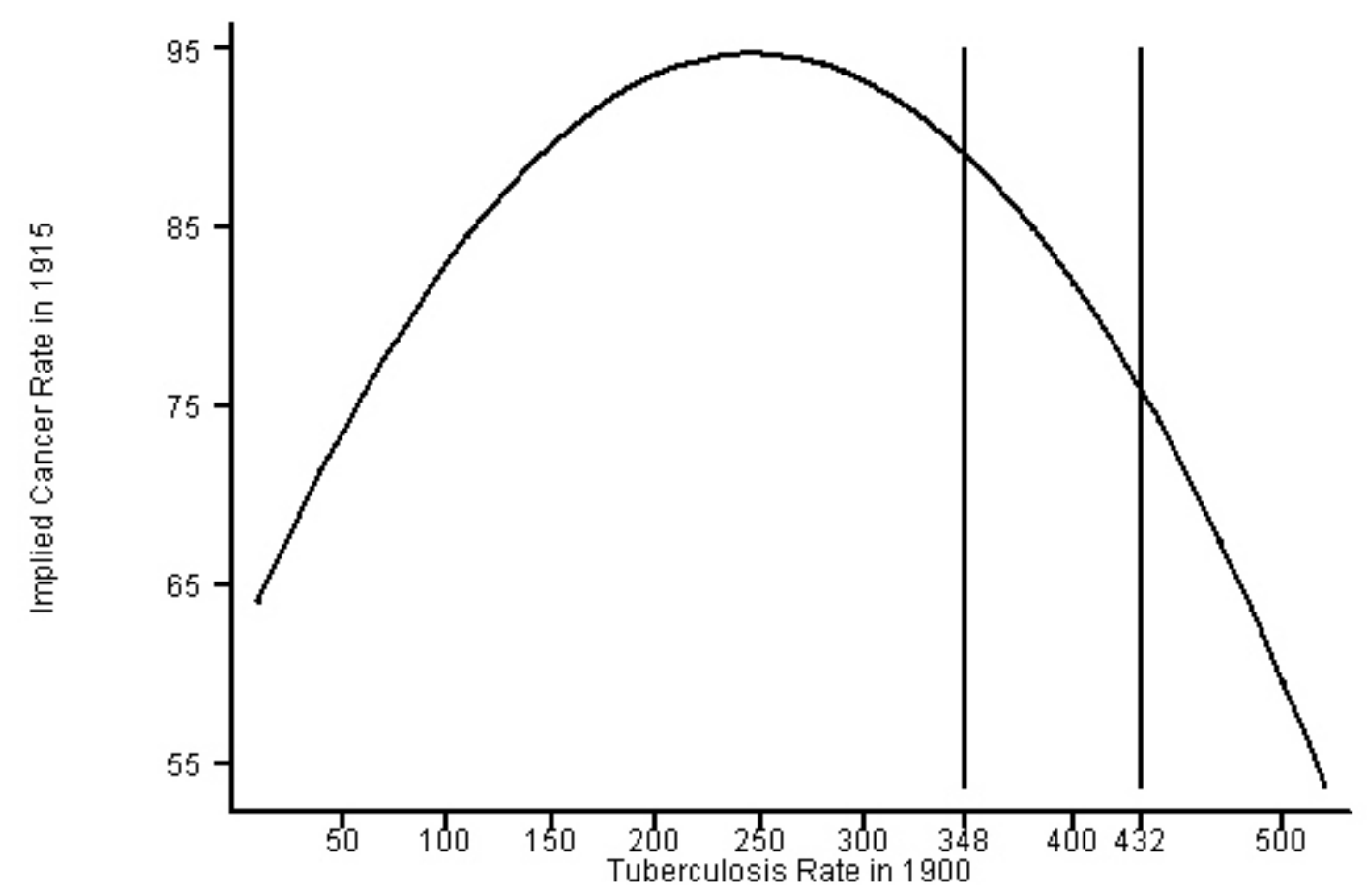

Figure 6. Estimated Relationship: Cancer in 1915 and Tuberculosis in 1900*

* Based on full-blown regression model.

Sources: United States, Mortality Statistics, 1900 and 1915. 


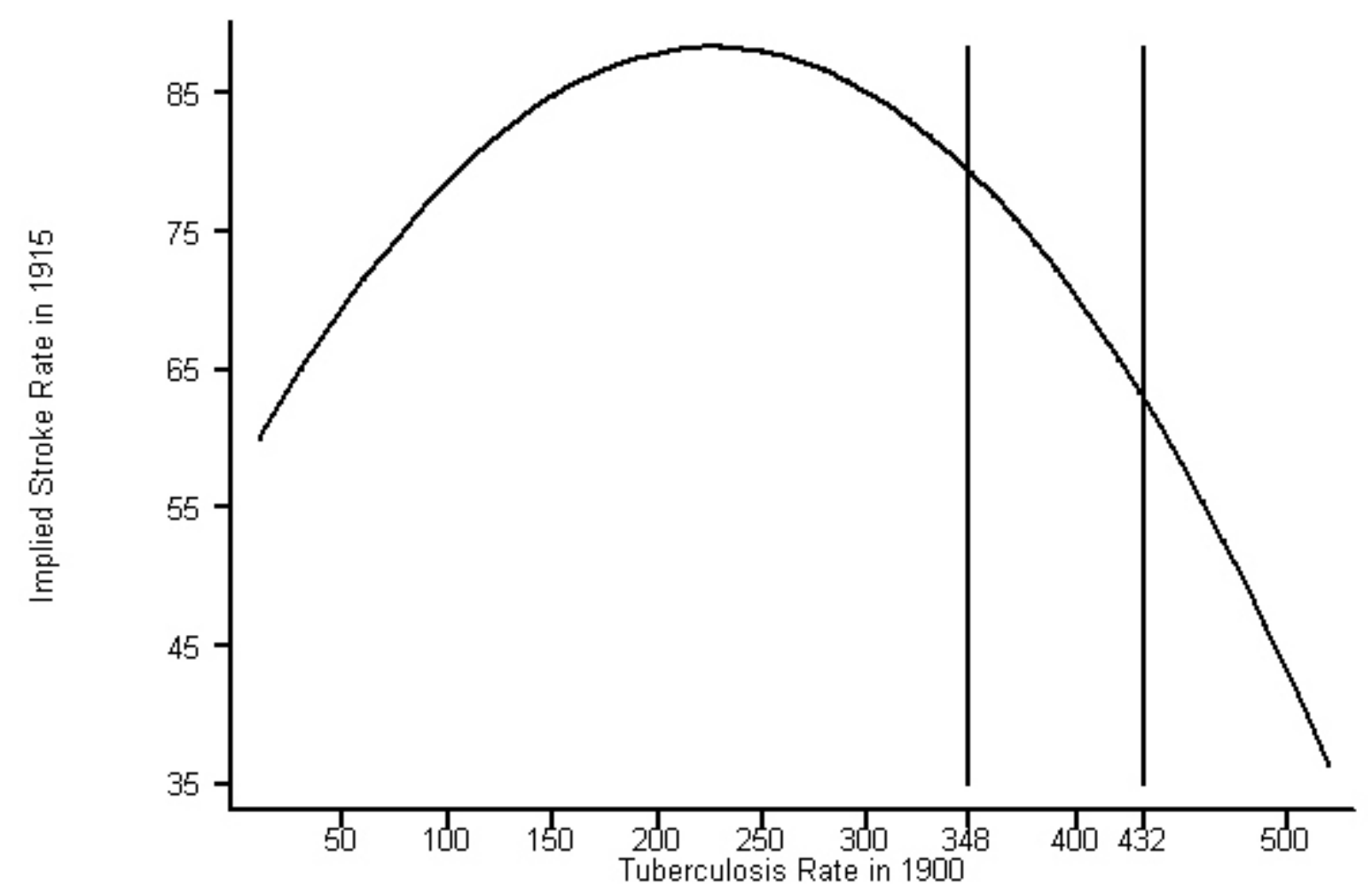

Figure 7. Estimated Relationship: Stroke in 1915 and Tuberculosis in 1900*

* Based on full-blown regression model.

Sources: United States, Mortality Statistics, 1900 and 1915. 


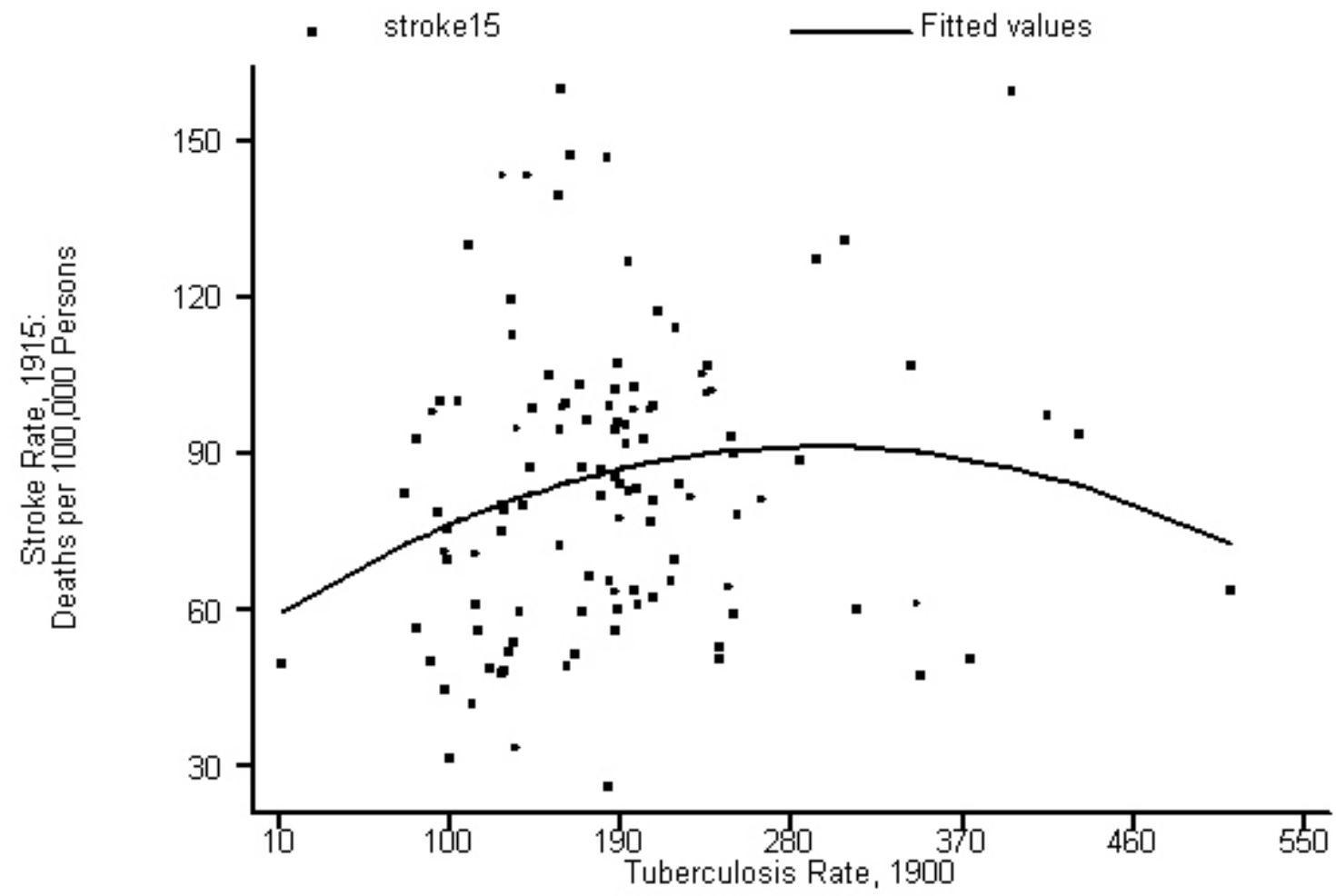

Figure 8. Stroke in 1915 and Tuberculosis in 1900: Raw Data

Sources: United States, Mortality Statistics, 1900 and 1915. 


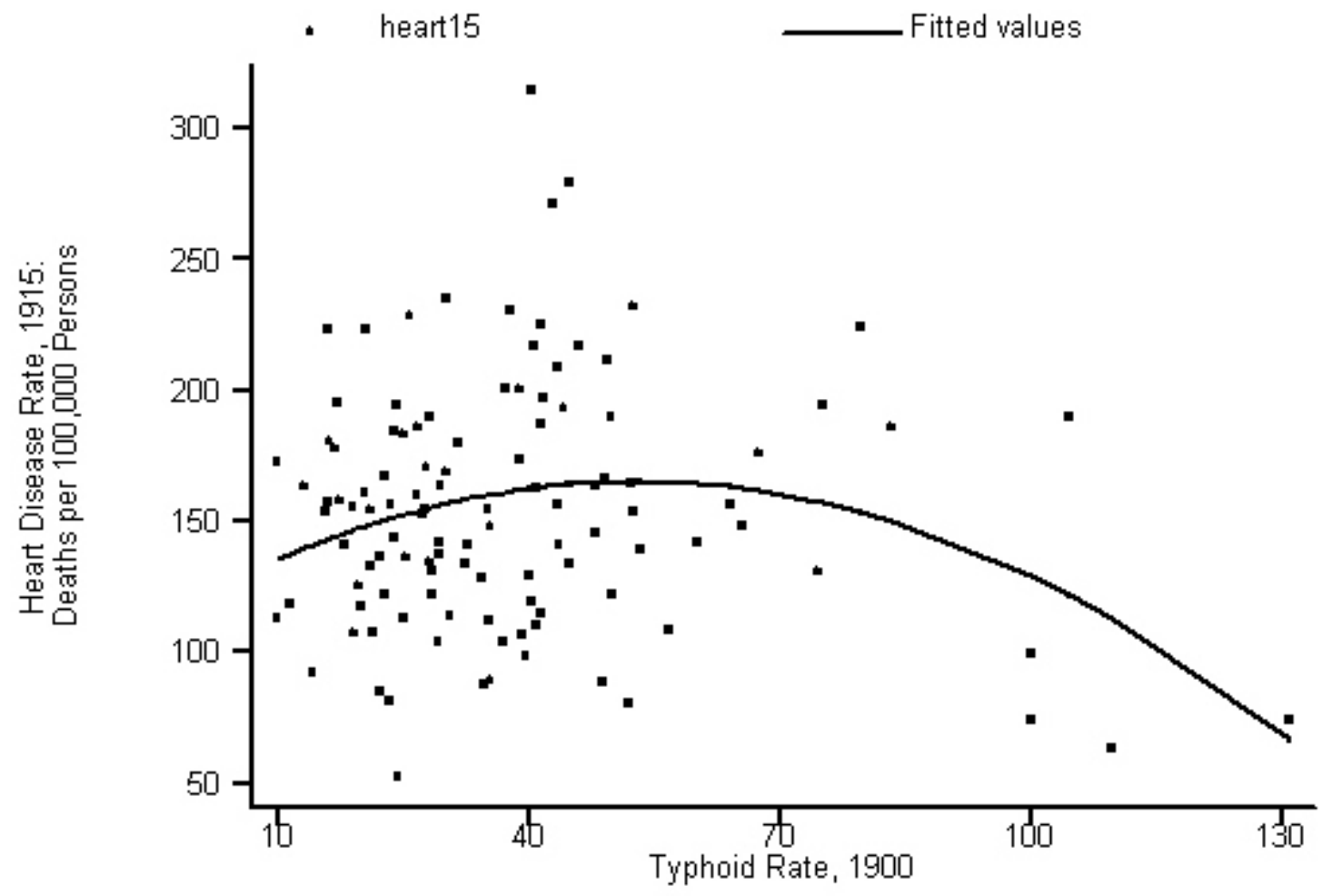

Figure 9. Heart Disease in 1915 and Typhoid in 1900: Raw Data

Sources: United States, Mortality Statistics, 1900 and 1915. 


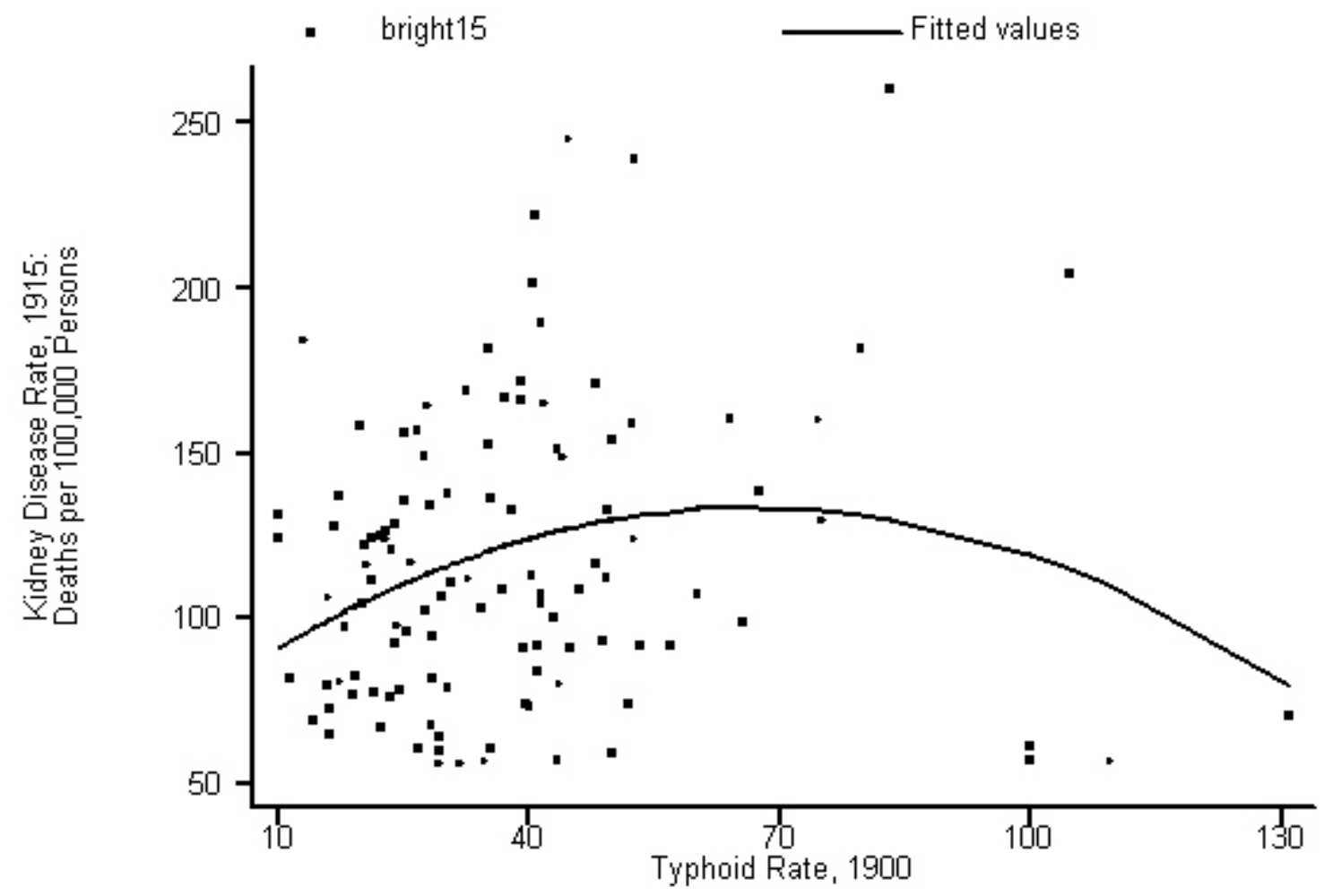

Figure 10. Kidney Disease in 1915 and Typhoid in 1900: Raw Data

Sources: United States, Mortality Statistics, 1900 and 1915. 